\title{
Estimations of statistical dependence as joint return period modulator of compound events - Part 1: Storm surge and wave height
}

\author{
Thomas I. Petroliagkis \\ Joint Research Center, Ispra, 21027, Italy \\ Correspondence: Thomas I. Petroliagkis (thomas.petroliagkis@ec.europa.eu) \\ Received: 18 May 2017 - Discussion started: 24 July 2017 \\ Revised: 12 May 2018 - Accepted: 15 June 2018 - Published: 12 July 2018
}

\begin{abstract}
The possibility of utilizing statistical dependence methods in coastal flood hazard calculations is investigated since flood risk is rarely a function of just one source variable but usually two or more. Source variables in most cases are not independent as they may be driven by the same weather event, so their dependence, which is capable of modulating their joint return period, has to be estimated before the calculation of their joint probability. Dependence and correlation may differ substantially from one another since dependence is focused heavily on tail (extreme) percentiles. The statistical analysis between surge and wave is performed over 32 river ending points along European coasts. Two sets of almost 35-year hindcasts of storm surge and wave height were adopted, and results are presented by means of analytical tables and maps referring to both correlation and statistical dependence values. Further, the top 80 compound events were defined for each river ending point. Their frequency of occurrence was found to be distinctly higher during the cold months, while their main low-level flow characteristics appear to be mainly in harmony with the transient nature of storms and their tracks. Overall, significantly strong values of positive correlations and dependencies were found over the Irish Sea; English Channel; and south coasts of the North Sea, Norwegian Sea, and Baltic Sea, with compound events taking place in a zero-lag mode. For the rest, mostly positive moderate dependence values were estimated even if a considerable number of them had correlations of almost zero or even a negative value.
\end{abstract}

\section{Introduction}

In the coastal and intertidal zones, high waves and extreme tidal surge events can occur simultaneously with extreme precipitation events and high river flows, leading to increased flood severity, duration, or frequency as highlighted in Svensson and Jones (2002, 2003, 2004a, b, 2005), Hawkes and Tawn (2000), and Hawkes et al. (2005). These interactions are generally referred to as coincident or compound events (IPCC, 2012). In the current Part 1, compound events of surge and wave are those events that coincidently are above a certain upper-percentile criterion (representing a critical threshold). A key component of any coincident event assessment is to understand the historical relationships between the different factors that may lead to a compound flood event. However, assumptions are often made regarding how these different factors and variables coincide or combine, typically leading to either an under- or overestimation of the probability of flooding (Coles et al., 2000). In reality, while some events may indeed occur independently from one another, others involve an interaction, or may have compounding consequences when they occur simultaneously, and need to be treated as partially dependent for the estimation of their joint probability or joint return period (https://www.niwa.co. nz/natural-hazards/faq/what-is-a-return-period, last access: 12 May 2018).

Joint probability values provide the likelihood of source variables taking high values simultaneously, resulting in a situation where flooding may occur. Acceptance of joint probability methods has been relatively sparse so far mainly due to the lack of information on dependence among source variables and the intrinsic difficulty in usage and interpretation 
of the methods as pointed out in the Australian Rainfall \& Runoff Project 18 (2009) and Bevacqua et al. (2017). The main concept of dependence as presented by Reed (1999) refers to the tendency of critical values of source variables to occur at the same time, resulting in an increase in frequency of an extreme event. This is because dependence is able to modulate the joint return period as documented in Hawkes (2004), Meadowcroft et al. (2004), White (2007), and the Australian Rainfall \& Runoff Project 18 (2009).

The method for estimating the probability of extreme values from a single variable is well understood and has been documented (Coles, 2001). Such probability is usually expressed in the form of a return period. In a similar way, the (joint) probability of two variables producing high or extreme values together, assumed to be fully independent or fully dependent, is also considered straightforward as explained in the Defra TR0 Report (2003). On the other hand, examples of coincident flood event studies, which incorporate a measure of the relationship between the input variables, are generally limited due to the complexity of the broader problem of coincident events (Bevacqua et al., 2017). Assessing the probability of flooding from the joint occurrence of high waves and high sea level values for instance is not an easy process, as high waves and storm surge tides may be attributed to the same prevailing storm system; thus, independence cannot and should not be assumed. Further, it is more complicated to estimate such conditional (joint) probabilities than those referring to totally independent events (http://onlinestatbook.com/2/probability/basic.html, last access: 12 May 2018). However, some approachable and userfriendly methods seem to exist for quantifying the statistical dependence between the input variables as noted in Hawkes (2004) and White (2007) and applied by Zheng et al. $(2013,2014)$ and Klerk et al. (2015).

In the case of independent events, the chance of one event occurring is not changed by the occurrence of the other event. However, if the occurrence of one event is dependent on the occurrence of a second event, then the events are termed conditional even if their correlation might be equal to zero. It should be stressed that correlation and dependence might differ substantially from one another. Two source variables may have low correlation, but there may exist considerable statistical dependence between them referring to their upper percentiles, where actually extremes reside. Further, it should be well established by now that correlation coefficients measure the degree of straight line or linear relationship only and that there are situations in which correlations are zero but where strong non-linear relationships exist among variables (Drouet Mari and Kotz, 2004).

Assuming independence between input variables might considerably underestimate the likelihood of flooding resulting in higher risk for the coastal community, since the conditional probability of both events occurring at the same time is different from the product of their individual probabilities (Blank, 1982). Similarly, assuming total dependence could be too conservative (Beersma and Buishand, 2004). What someone should anticipate is the fact that dependence is likely to occur when different processes are linked to some common weather (forcing) conditions. It may also arise when the same process is studied at different spatial locations or over different periods (Coles et al., 2000). In an estuarine or riverine area, an example would be a storm accompanied by high winds and intense precipitation phenomena. For such cases where two (or more) variables, capable of producing high-impact events, are not totally independent or totally dependent, but may be partially dependent, probabilistic approaches are limited in both their reliability and scope (White, 2007).

In this work, the possibility of utilizing statistical dependence methods in coastal flood hazard calculations is investigated, since an estimation of the joint probability (joint return period) is necessary for the calculation of compound flood hazard in a coastal area. Such an approach points to taking into account the variability and exact nature of extreme conditions. The basic idea behind joint probability theory is to identify extreme data within each of the input variables and statistically correlate their linkages and risk of simultaneous occurrence. Therefore, it seems quite important to find an appropriate way to undertake this task. Understanding such risks, created by the combination of extreme events, is crucial for the design of adequate and cost-effective river and coastal defences as well as for the true estimate of flood risk as highlighted in Merz et al. (2009) and the Australian Rainfall \& Runoff Project 18 (2009).

The current work focuses on data preparation, parameter selection, methodology application, and estimation of both correlation and statistical dependence between source variables. It also focuses on the prevailing (higher frequency) and dominant (higher intensity) low-level wind conditions over a set of preselected (top 80) extreme compound events. The critical time period during which such extremes take place is also analysed based on monthly frequency values of occurrence. The dependence analysis utilizes 32 river ending points selected to cover a variety of geographical areas along European coasts. The variable pairs presented in this report, which include enough information for calculations, are storm surge and wave height, relevant to most coastal flood defence studies. Two main time intervals were considered for the estimation of maximum values: the half-day interval $(\max 12)$ and the 1-day interval (max24).

This study represents the first part (i.e. Part 1) of the investigation, while Part 2 (storm surge and river discharge) and Part 3 (wave height and river discharge) are to follow. The reasoning behind such a separate investigation (by parts) is to allow for the reader to gain a deeper and better understanding of the interaction between different components contributing to a compound coastal event.

In Sect. 2, data and methods used in this study are presented, while results are shown in Sect. 3. A discussion and conclusions are contained in Sects. 4 and 5 respectively. 


\section{Data and methodology}

\subsection{Statistical dependence $(\chi)$}

The main concept of the so-called dependence measure $\chi$ (chi) is related to two or more simultaneously observed variables of interest - such as in this case storm surge and wave height - known as observational pairs. If one variable exceeds a certain extreme (high-impact) threshold, then the value of $\chi$ represents the risk that the other variable will also exceed a high-impact threshold as explained in Hawkes (2004), Svensson and Jones (2004a, b), and Petroliagkis et al. (2016).

Following Coles et al. (2000), if all of the extreme observations of two variables exceed a given threshold at the same time, this indicates total dependence $(\chi=1)$. If the extreme observations of one variable exceed a given threshold but the second variable does not, this indicates total independence $(\chi=0)$. Similarly, if the extreme observations of one variable exceed a given threshold but the other variable produces lower observations than would normally be expected, this indicates negative dependence $(\chi=-1)$. In practice, hydro-meteorological analyses based on real data often lead to an assessment of complete independence that could result in an underestimation of the joint probability of concurrent extreme events, whereas an assumption of complete dependence could result in an overestimation of joint probabilities (Beersma and Buishand, 2004). In reality, as variables reach their extreme values, a special methodology of estimating statistical dependence could be utilized like the one documented in Buishand (1984). A brief description of this method based on Coles et al. (2000) is contained in the Statistical Supplement, while the basic theory behind the utilization of an optimal copula function refers to Nelsen (1998), Joe (1997), Currie (1999), and Wahl et al. (2015).

\subsection{River ending points}

The current statistical (dependence) analysis is focused on 32 RIEN (RIver ENding) points that have been selected to cover a variety of riverine and estuary areas along European coasts. These points were selected mainly for their proximity to tide gauge recorders, although not many observations were found suitable to be exploited due to the lack of long-period coincident wave (buoy) observations in the nearby area. The sea areas used in the study refer to the Mediterranean Sea (central and northern Adriatic Sea, Balearic Sea, Alboran Sea, and Gulf of Lion), western Iberian coasts, north Iberian coasts, Bay of Biscay, Irish Sea, Bristol Channel, English Channel, North Sea, Norwegian Sea, Baltic Sea, and Black Sea. A map showing the position of RIEN points used in the study is shown in Fig. 1. Additional details can be found in Table S1 in the Technical Supplement, containing the exact location (lat, long) of all RIEN points.
As already mentioned, long-period water level data coinciding with wave observations directly or very close to the exact sites of interest (RIEN points) were not available, with the exception of the Rhine River RIEN. For this RIEN, concurrent (close-by) observations with no gaps in sea level, astronomical tide, storm surge, or wave height from a closeby wave buoy were available for a period of about 3 years (1114 days).

\subsection{Storm surge hindcasts}

Storm surge is an abnormal rise of water generated by a storm over and above the predicted astronomical tide values (http://www.nhc.noaa.gov/surge/faq.php, last access: 12 May 2018). In "observation mode", storm surge is calculated as a residual by subtracting harmonic tidal predictions from the observed sea level (Horsburgh and Wilson, 2007); depending on inclusion of the non-linear interaction of tides and storm surges, this "residual" can include tide-surge interaction as well. In this study, tide-surge interaction, harmonic prediction errors, and timing errors were not taken into consideration. On the other hand (e.g. in hindcast model simulation mode) a similar residual refers to the genuine meteorological contribution to sea level that represents the storm surge term. It should be pointed out that the effect of wind and atmospheric pressure (inverse barometric effect) is contained in both the residual and storm surge terms. Based on this, it becomes clear that all data (storm surge) sets used in the study contain the effect of the inverse barometric effect besides the effect due to wind. This is the reason why the dedicated model (Delft3D-FLOW) uses as input both ERAInterim (Dee et al., 2011) wind and pressure fields.

For assessing dependence, a full set of coincident observation data is needed over a relatively long time period (at least 5 years) for the primary variables, as pointed out in the Defra TR2 Report (2005). Such a demanding requirement is too difficult if not impossible to be fulfilled only by observational data over all 32 RIEN points, so the methodology of simulating data observations by modelling (hindcasts) was applied, resulting in a set of long period model simulations (hindcasts) for the two primary variables (surge and wave).

For storm surge hindcasts, the Delft3D-FLOW hydrodynamic module of the open-source model Delft3D (Deltares, 2014) was used to compile storm surge time series due to the combined effect of the wind and the atmospheric pressure gradient. The model (Delft3D-FLOW) has been used successfully in similar applications (hindcasts) in the past (Sembiring et al., 2015). In this case, 3-hourly long-term storm surge series for the 32 RIEN points were compiled from a similar hindcast set to that used in Vousdoukas et al. (2016) to estimate projections of extreme storm surge levels across Europe. This was obtained by forcing the Delft3D-FLOW module by 6-hourly wind and pressure fields retrieved from the European Centre for Medium-Range Weather Forecasts (ECMWF) ERA-Interim reanalysis data set (Dee et al., 


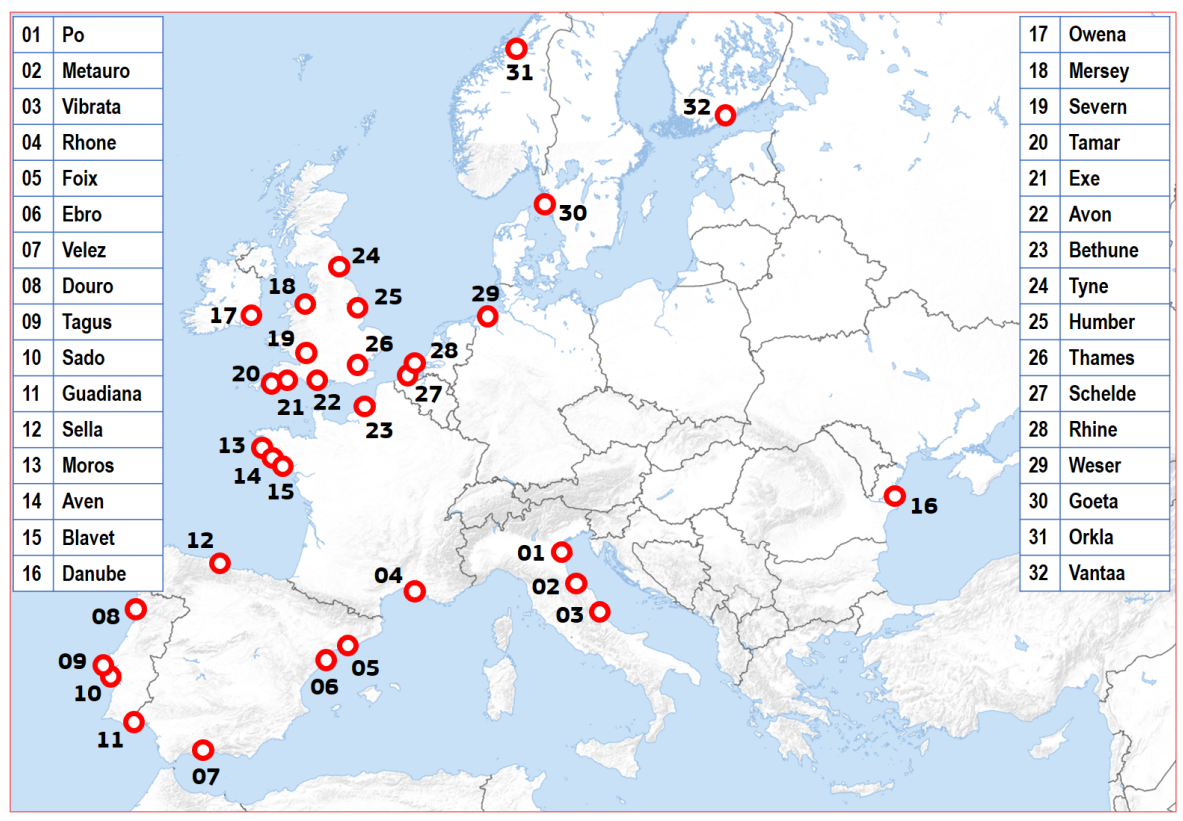

Figure 1. Positions of the 32 RIEN (river ending) points used in the study. Names refer to river names. Exact positions (lat, long) of RIEN points are given in Table S1 (Technical Supplement).

2011). The ERA-Interim (hereafter, ERAI) is a global atmospheric reanalysis ranging from 1979 to present. ERAI's main products include global atmospheric and surface parameters from 1 January 1979 to present, at T255 spectral resolution $(\sim 75 \times 75 \mathrm{~km})$ on 60 vertical levels.

Storm surge hindcasts (1 January 1980 to 30 November 2014) span a total interval of 12753 days ( $~ 35$ years), having a time separation of $3 \mathrm{~h}$ with a spatial resolution of about $0.2^{\circ}(\sim 25 \times 25 \mathrm{~km})$ along the European coastline and the NE Atlantic Ocean areas. Hindcast storm surge levels were validated with measurements from 110 tide gauges from the Joint Research Center (JRC) Sea Level Database (http://webcritech.jrc.ec.europa.eu/SeaLevelsDb, last access: 12 May 2018). Details can be found in Vousdoukas et al. (2016). The relative rms (root mean squared) error for more than 105 stations was found to be less than $20 \%$ and for more than 60 stations less than $15 \%$. More specifically, the validation performance of hindcasts is contained in the scatter plot of Fig. 4 (Vousdoukas et al., 2016) for both rms error in metres (a) and as a percentage of the SSL (storm surge level) range (b) for all the available tidal gauge stations. Further, even if there were cases where some extreme storm surge levels were underestimated by the hindcasts, the overall model performance is considered to be satisfactory.

\subsection{Wave height hindcasts}

In many applications, a selection of heights and periods of the higher waves in a wave train seem to be of practical significance. For this reason, the average height of the highest one-third of the waves, after eliminating the ripples and waves of height less than $30 \mathrm{~cm}$, is considered as a useful statistical measure. This average is commonly named "significant wave height" (Sverdrup and Munk, 1946), and it is utilized in the current study.

As in the case of storm surge, global fields of 3-hourly (significant) wave data were assembled by utilizing a set of hindcasts produced with the latest stand-alone version of the ECMWF Ocean Wave Model (ECWAM; for details see Bidlot et al., 2006; Bidlot, 2012; ECMWF, 2015; Phillips et al., 2017). The ECWAM model was run on a $0.25^{\circ}$ lat-long global grid $(\sim 28 \times 28 \mathrm{~km})$ with fixed water depth (mean bathymetry, i.e. no surges or tides) being forced by neutral wind fields (as forcing terms) extracted from the ERAI reanalysis. Due to such resolution limitations, the model may not represent the best source of wave data for a particular single coastal location, but it does offer consistent coverage over the area of this study within an acceptable degree of accuracy. The reason is that, even if model resolution does not seem capable of simulating local coastal topographical details, the main characteristics of the large-scale wave evolution are expected to be captured (based on in situ wave observation data provided by Jean-Raymond Bidlot (ECMWF) and used for validation and compiling Figs. 2 and 3 ). For more details on wave validation and verification data, see https://www.ecmwf.int/en/newsletter/150/meteorology/ twenty-one-years-wave-forecast-verification (last access: 12 May 2018).

For each RIEN point, 3-hourly hindcast wave data time series for the period of 1 January 1979 to 31 December 2015 were assembled (13 149 days) by considering the closest 


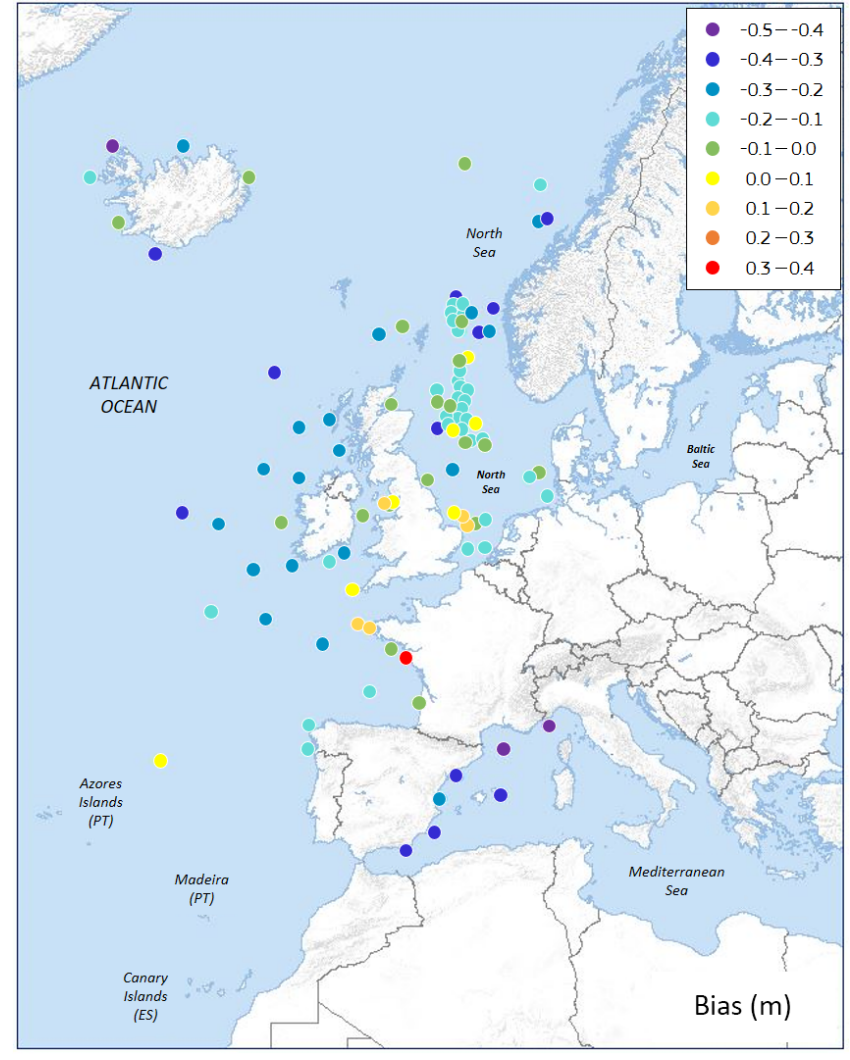

Figure 2. Bias values (m) for wave hindcasts during 1996 to 2015.

model grid (sea) point, with no missing records. The resultant records consist of significant and maximum wave height values, mean wave period, and mean wave direction. The ECWAM model has been configured in its CY41R1 parametrization cycle employing 30 frequencies and 36 directions for the wave spectra (ECMWF, 2015).

Validation of wave hindcasts was carried out utilizing a set of available data collected from 101 buoys over European and NE Atlantic Ocean areas during the period from 1996 to 2015. The exact position of the buoys used in validation is shown in Fig. 2 (also in Fig. 3). Both bias and rms error scores were considered, and results are shown in Fig. 2 for bias and in Fig. 3 for rms error. Both scores (bias and rms error) suggest that the model's performance was satisfactory, although bias lags slightly in quality compared to rms error mainly due to the weak ERA-Interim winds that seem to affect the bias more than rms error. Additional validation details focusing on extremes are contained in Sect. S2 of the Technical Supplement.

It should be noted that the maximum common time interval of 12753 days ( $\sim 35$ years) for surge and wave variables was considered for the statistical (dependence) analysis over the 32 RIEN points of this study. Further, as already stated above, both sets of hindcasts had already been validated (Vousdoukas et al., 2016; Phillips et al., 2017), so em-

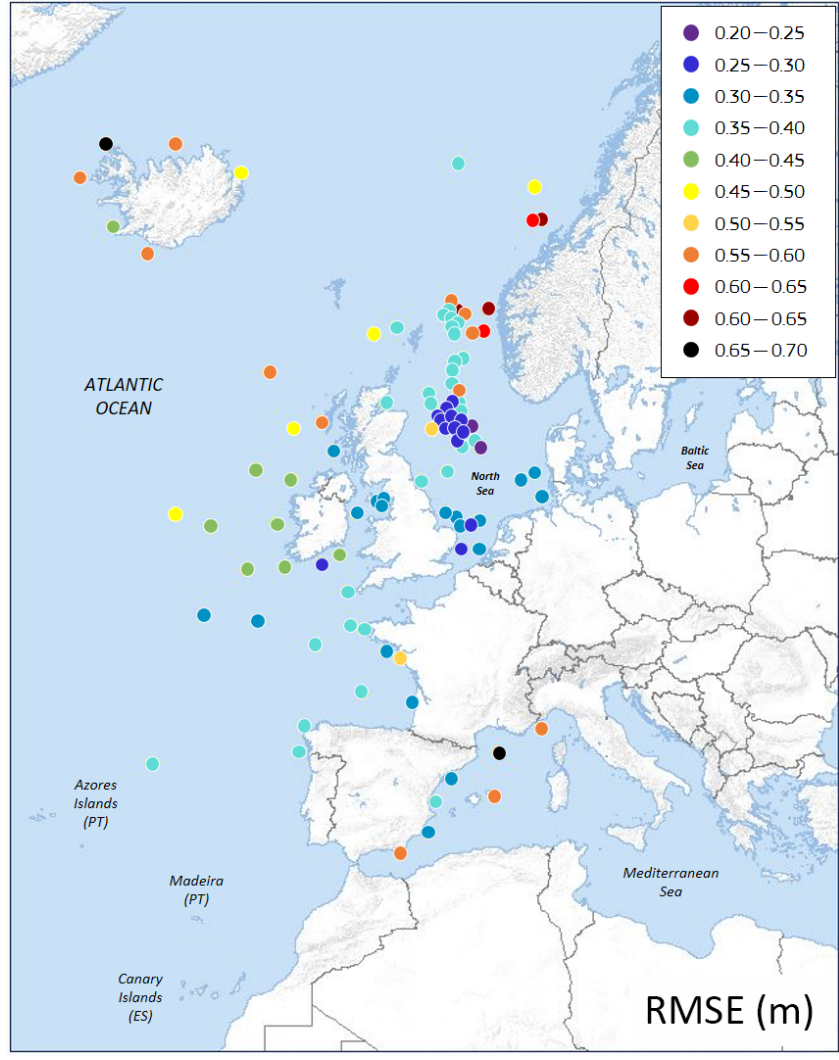

Figure 3. As in Fig. 2 but for rms error (RMSE) values.

phasis was placed on demonstrating the methodology of estimating the type and strength of statistical dependence. Such an investigative approach was performed initially over the ending point of the Rhine River (NL) with very satisfactory results (see next Sect. 2.5), while the same approach (of estimating statistical dependence) was adopted for the rest of the ending points (RIENs).

\subsection{Joint validation for the RIEN of the Rhine River (NL)}

A joint validation of surge and wave hindcasts utilizing a relatively long series of surge and wave observations close to Rockanje (RIEN of the Rhine River) was performed to test the quality of hindcasts during the common period of observation records. For this task, storm surge observations close to Rockanje were downloaded from MATROOS (Deltares Multifunctional Access Tool foR Operational Oceandata Services - http://noos.deltares.nl/, last access: 12 May 2018) database. Such surge observations were recorded by the nearby Hook van Holland $(\mathrm{HvH})$ tide gauge recorder positioned about $15 \mathrm{~km}$ northeast of Rockanje (as depicted in Fig. 4). Referring to observation parameters, sea level is the recorded still (i.e. in the absence of waves) water level, and surge is the difference between sea level and predicted tide for that time and location. Similarly, a set of significant wave 


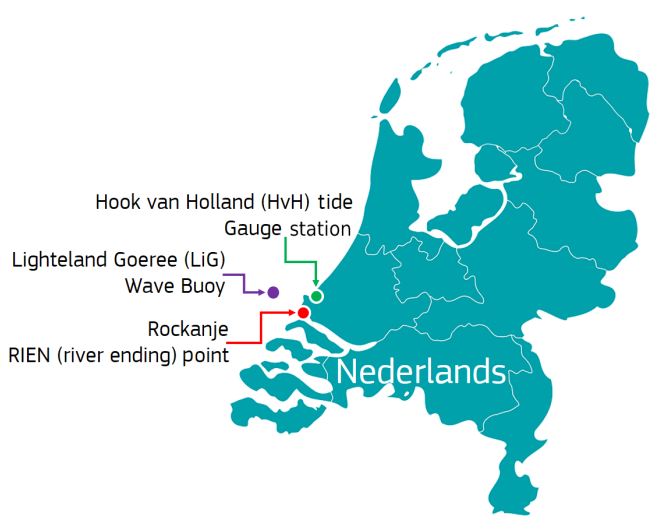

Figure 4. Position of HvH tide gauge station, Rockanje RIEN point, and Lichteiland Goeree I (LiG) wave buoy (NL).

height observations were retrieved from the close-by wave buoy platform of Lichteiland Goeree I (LiG) moored in the North Sea about $55 \mathrm{~km}$ northwest of Rockanje (see details in Fig. 4).

A common time interval of 1114 days (from 22 September 2010 until 9 October 2013) with no gaps was selected for validating surge (SUR) and wave (WAV) hindcast data sets. Such surge and wave hindcasts were different to the ones referring to Rockanje RIEN point since they were performed as close as possible to the exact positions of the HvH tide gauge recorder (SUR) and LiG wave buoy (WAV) for obvious reasons. Both types of observation, i.e. surge over $\mathrm{HvH}$ and wave height over LiG, were made on an hourly basis, so daily $(\max 24 \mathrm{~h})$ and half-day $(\max 12 \mathrm{~h})$ maximum values were calculated. In harmony with observations, 3-hourly storm surge and 3-hourly wave hindcasts were transformed to daily $(\max 24)$ and half-day $(\max 12)$ maximum hindcast values. Daily maximum (max24) levels of SUR hindcasts for $\mathrm{HvH}$ were compared against daily maximum observations measured by the $\mathrm{HvH}$ tide gauge over the reference period of 1114 days. The closest storm surge point used in this analysis was situated $\sim 20 \mathrm{~km}$ to the north of $\mathrm{HvH}$ (North Sea).

Figure 5 (upper panel) contains the scatter plot of surge hindcasts against observations in max 24 mode. It appears that SUR hindcasts are in most cases lower than their corresponding observation values. This difference might be attributed to the relatively low temporal and spatial resolution of ERA-Interim forcing terms, although hindcasts overall were found capable of coping well with both the timing and magnitude of extremes.

An example of such an extreme that took place on 5 January 2012 is shown in Fig. 5 (lower panel), which contains a subsection of SUR hindcasts plotted together with surge observations over $\mathrm{HvH}$. This extreme was selected as a multipurpose demonstrative example (see also Fig. 7 for corresponding maxima of WAV values during the same period and Sect. 3.5, where the de-clustering technique of the peaksover-threshold (POT) approach is explained). It is evident
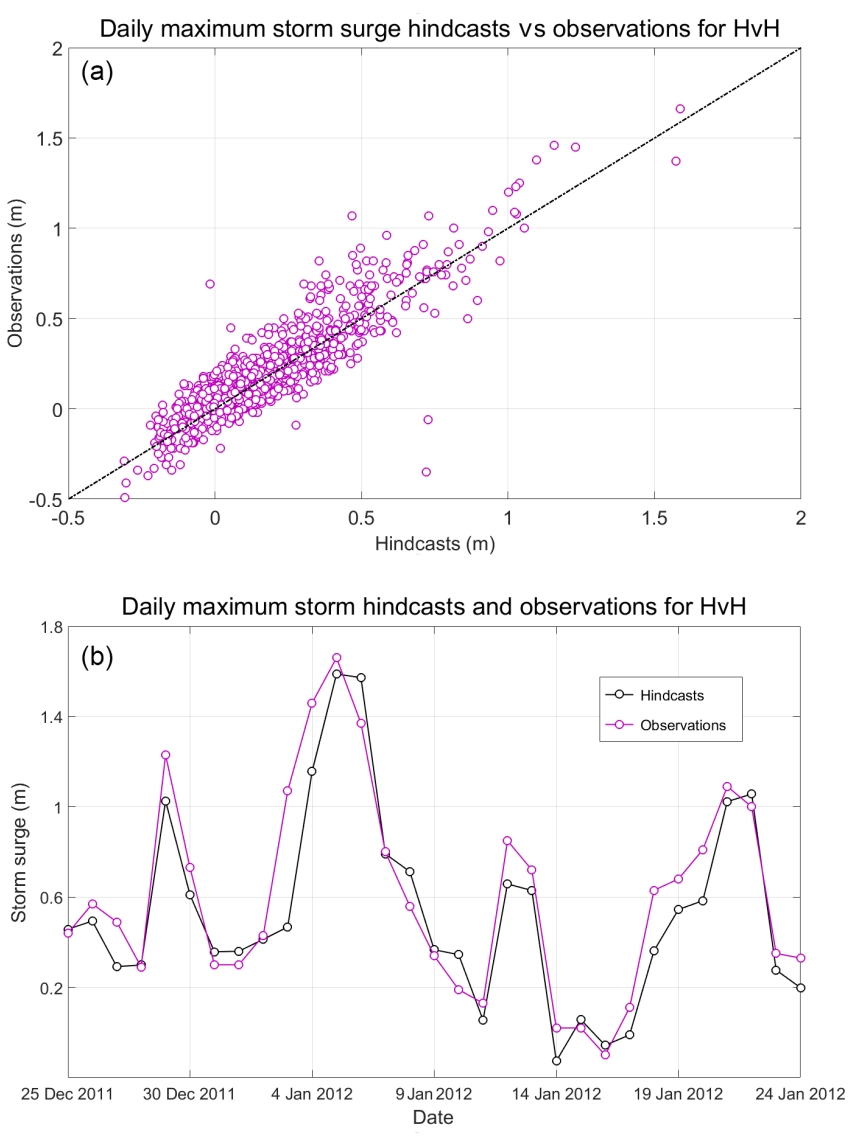

Figure 5. Scatter plot of surge hindcasts against observations for $\mathrm{HvH}$ (a) and a subsection of hindcast and observation values during 25 December 2011 to 24 January 2012 (b).

that, although SUR hindcasts have a tendency to underestimate observations, the model simulations seem able to resolve both the magnitude and the duration of storm events relatively well. The storm surge peak of 5 January 2012 was found to be linked to a very intense extratropical cyclone (Storm Ulli/Emil) affecting the greater area of the North Sea. The position and details of the storm are contained in the surface weather map of 12:00 UTC of 3 January 2012 shown in Fig. 6 (upper panel). The corresponding (12:00 UTC) satellite picture capturing Storm Emil is contained in the same Fig. 6 (central panel).

When studying closely both surge hindcast and observation values referring to Storm Emil (lower panel of Fig. 5), it seems that hindcasts could resolve and simulate well both the phase and the magnitude of such an extreme event. It is important to realize that such events are linked to intense pressure gradients such as those clearly seen in Fig. 6 (lower panel) prevailing during the late-night hours of 5 January 2012. Besides the intensity of pressure gradients, the orientation of isobars, which was almost vertical to the coasts of Holland (as indicated by a purple arrow), also strongly contributed to the extremity of the event. 

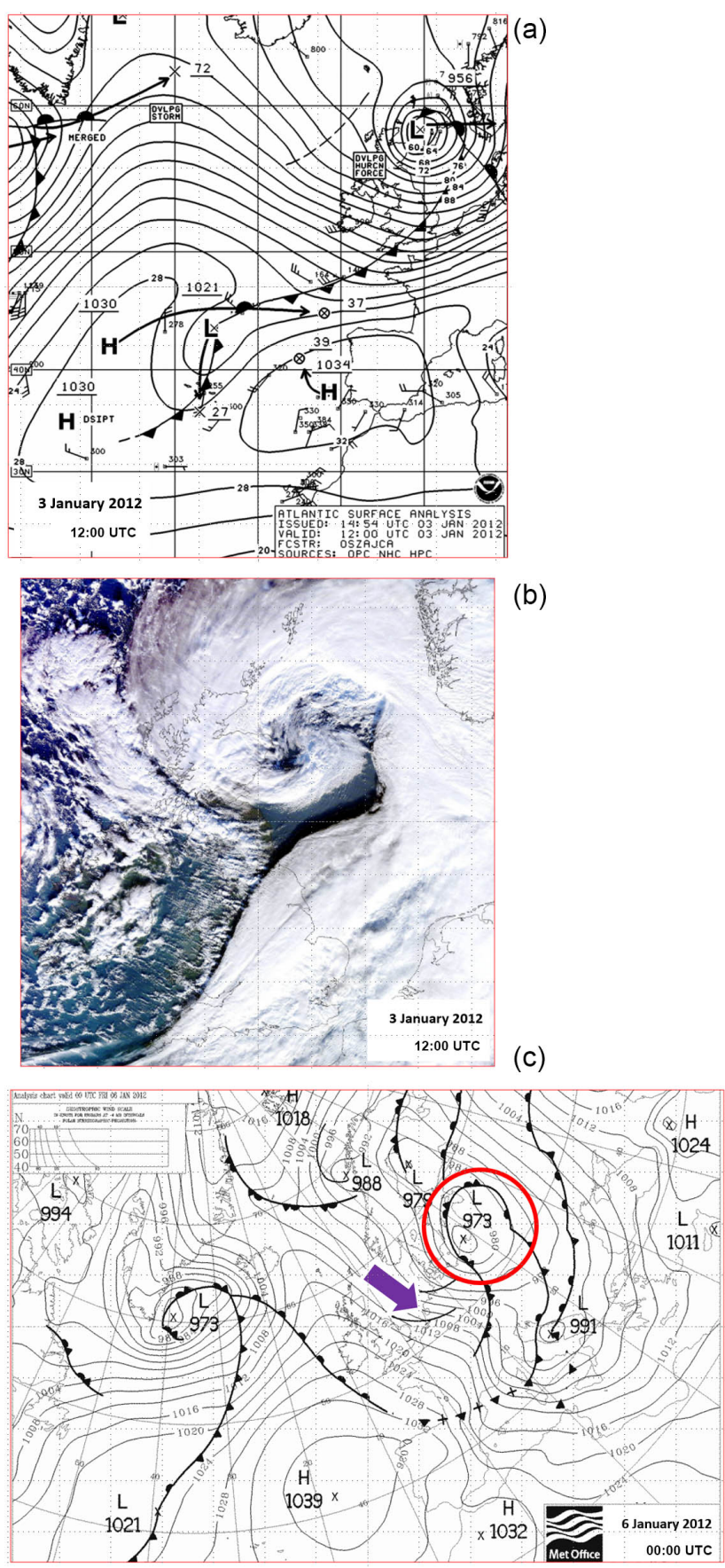

Figure 6. Surface map (a) and its corresponding satellite image (b) valid for 3 January 2012 at 12:00 UTC. Surface weather map in the late hours (midnight) of 5 January 2017 (c).

Overall, storm surge hindcasts were found to have a negative bias (defined as difference between the mean of hindcasts and the mean of observations; see details in http://www.cawcr.gov.au/projects/verification/, last access: 12 May 2018) of about $-2.65 \mathrm{~cm}$. It was also found that hindcast and observation values exhibit a very strong corre-
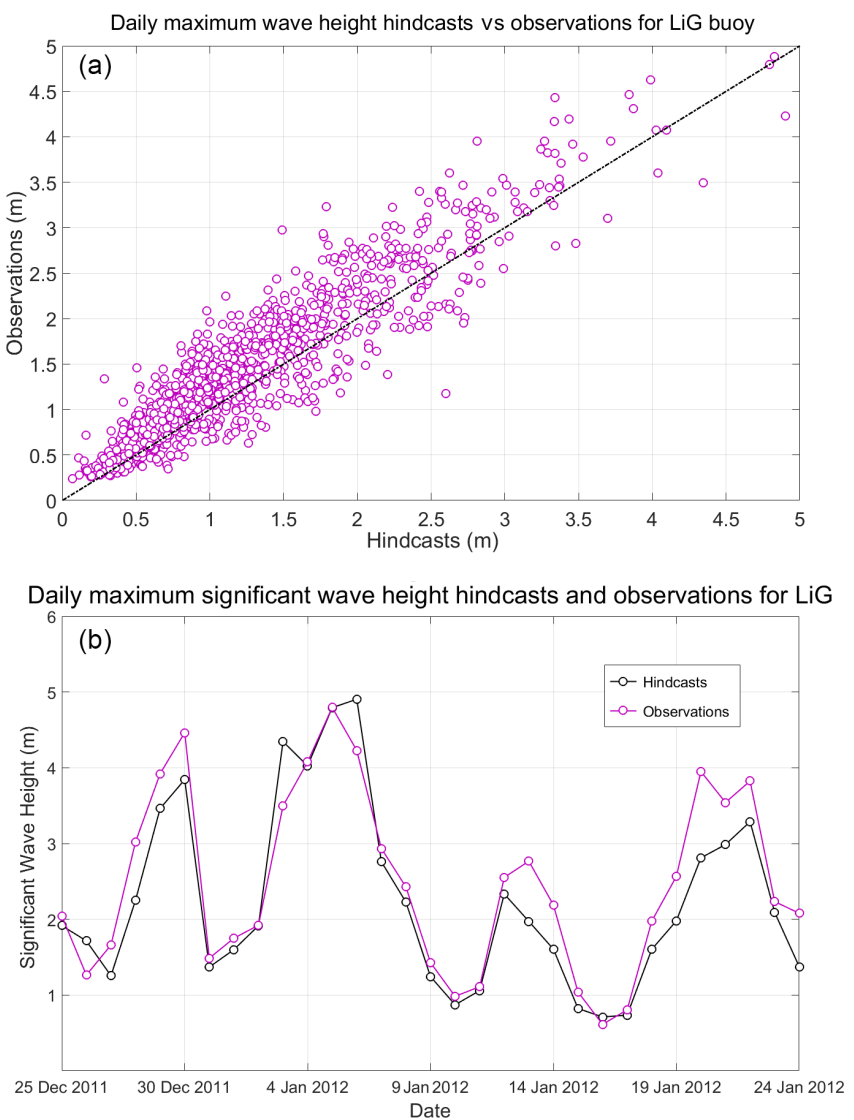

Figure 7. Scatter plot of wave hindcasts against observations (a) and a subsection of hindcast and observation values during $25 \mathrm{De}-$ cember 2011 to 24 January 2012 (b).

lation reaching a value of $\sim 0.90$, while slightly lower correlation was found for $\max 12(0.88)$.

Similarly, daily maximum $(\max 24)$ values of significant wave height (WAV) were compared against daily maximum values of observations measured at the LiG wave buoy platform as shown in Fig. 7 (upper panel). The closest wave model point used in this analysis was situated $\sim 9.5 \mathrm{~km}$ northwest of the position of the LiG platform. As in the storm surge case, WAV hindcasts are in most cases lower than their corresponding observation values.

As mentioned already, this might be due to the smoothness of ERAI forcing terms not possessing the required resolution to resolve the exact magnitude of wind components. The systematic bias of wave hindcasts was found to be relatively small, being equal to $20.30 \mathrm{~cm}$. Wave hindcasts were found to exhibit a very strong correlation value $(\sim 0.92)$ to observations, while similar (slightly lower) correlation was found for max 12 data pairs $(\sim 0.90)$.

As in the case of SUR hindcasts, Fig. 7 (lower panel) contains a subsection of time series of both WAV hindcasts and observations (with dates being identical to the previous SUR case). WAV hindcasts appear to be lower than observations; 
besides the unavoidable smoothness of ERAI fields, another explanation for such deviation might be the proximity of the LiG buoy to the coast. It is well known that enclosed areas and near-shore locations are indeed much more difficult to model (http://www.ecmwf.int/en/newsletter/150/ meteorology/twenty-one-years-wave-forecast-verification, last access: 12 May 2018).

Regarding the example (SUR) already presented in the lower panel of Fig. 5, the storm surge extreme of 5 January 2012 was found to be in harmony with the significant wave height extreme observed during the same max 24 interval (shown in the lower panel of Fig. 7). This is also an indication that storm surge and wave compound extremes are linked to the same weather system (Storm Emil) with a clear tendency to take place in a zero-lag time mode over the south coasts of the North Sea.

The obvious agreement between surge hindcasts and observations (Fig. 5) is a clear indication of the model's (Delft3D-FLOW) ability to efficiently simulate observations (over the whole spectrum of observations) in hindcast mode with wind components and mean sea level pressure from the ECMWF ERA-Interim reanalysis data set as input parameters. Similarly, the obvious agreement between wave hindcasts and observations (Fig. 7) is a clear indication of the model's (ECMWF/ECWAM) ability to efficiently simulate observations in hindcast mode with wind components from the ECMWF ERA-Interim reanalysis data set as input parameters.

Indicative examples of such capabilities can be seen in Tables S4 and S5 of the Technical Supplement, revealing that hindcasts above all were capable of identifying and resolving all seven compound events (based on $98.5 \%$ percentile threshold) that took place during the common time interval of 1114 days over the $\mathrm{HvH}$ area of interest.

Since this study is focused on maxima taking place over 12 and $24 \mathrm{~h}$ based on a $3 \mathrm{~h}$ set of hindcast values, timing errors were investigated over the Rhine River (NL) ending point, and the overall conclusion has been that hindcasts were able to pick up similar (to observations) maxima during both the 12 and $24 \mathrm{~h}$ intervals. Details and examples of the ability of hindcasts to identify and resolve compound events of surge and waves are contained in Sect. S3 of the Technical Supplement.

Further, an extra investigation based on extreme values of observations (during the common time interval of 1114 days) exceeding a variety of percentile values for the RIEN of the Rhine River revealed that both storm surge and corresponding wave height hindcasts were able to capture (resolve) almost all of the 12 and $24 \mathrm{~h}$ extremes (not necessarily compound ones) on the same (correct) day but with a weaker intensity (i.e. with a correct footprint of lesser intensity).

\section{Results}

The main tools for estimating statistical dependence $(\chi)$ are briefly summarized in the next section (Sect. 3.1). Besides the ability of surge and wave hindcasts to correctly simulate observations over the $\mathrm{HvH}$ tide gauge and LiG wave buoy platforms respectively (as analysed in Sect. 2.5), their potential for resolving the correct type and strength of both correlation and dependence between primary variables in a joint (compound) mode environment is investigated over a common period of 1114 days in Sect. 3.2. Referring to the full span of hindcasts, analytical maps and tables have been assembled containing both correlation and dependence values between surge and wave over the 32 RIEN points considered in this study.

Both correlation and dependence values were estimated over maximum values of surge and wave during 12 and $24 \mathrm{~h}$ intervals (labelled as max 12 and max 24 respectively). These results are presented in Sect. 3.3 (southern European areas) and Sect. 3.4 (northern European areas). An evaluation of the low-level flow during the top 80 extreme compound events utilizing wind rose diagrams is contained in Sect. 3.5. The critical period (of the year) for such high-impact events to take place is also assessed by considering monthly frequencies of occurrence.

\subsection{Main tools for estimating statistical dependence}

The main tools for assessing dependence between surge and wave were a set of Matlab routines (mat_chi) for estimating the asymptotic behaviour of statistically dependent variables. Other Matlab routines such as mat_chibar (see details and examples in the Statistical Supplement) for assessing the asymptotic behaviour of statistically independent variables were also used, and the main findings are contained in Tables S6 and S7 of the Technical Supplement. Besides Matlab functions, additional routines from the statistical package R, namely "taildep" of module extRemes and "chiplot" of module evd (extreme-value distributions), were used to estimate and inter-compare $\chi$ values (see details in the Statistical Supplement).

An optimal threshold of $\sim 2.3$ events on a yearly basis was able to provide quite stable dependence graphs (see details in the Statistical Supplement), while the maximum strength of almost any compound (surge and wave) event was found to take place during the same $24 \mathrm{~h}(\max 24)$ time or during the same $12 \mathrm{~h}$ (max12) period corresponding to zero-lag mode. Exceptions were found for Rhône, Ebro, Danube, Thames, and Goeta RIEN points with a 1-day lag (2 half-days in the case of max12), suggesting that storm surge values were (slightly) more highly correlated with wave height values of the previous day. Results in Tables and Figures refer to zerolag values. 

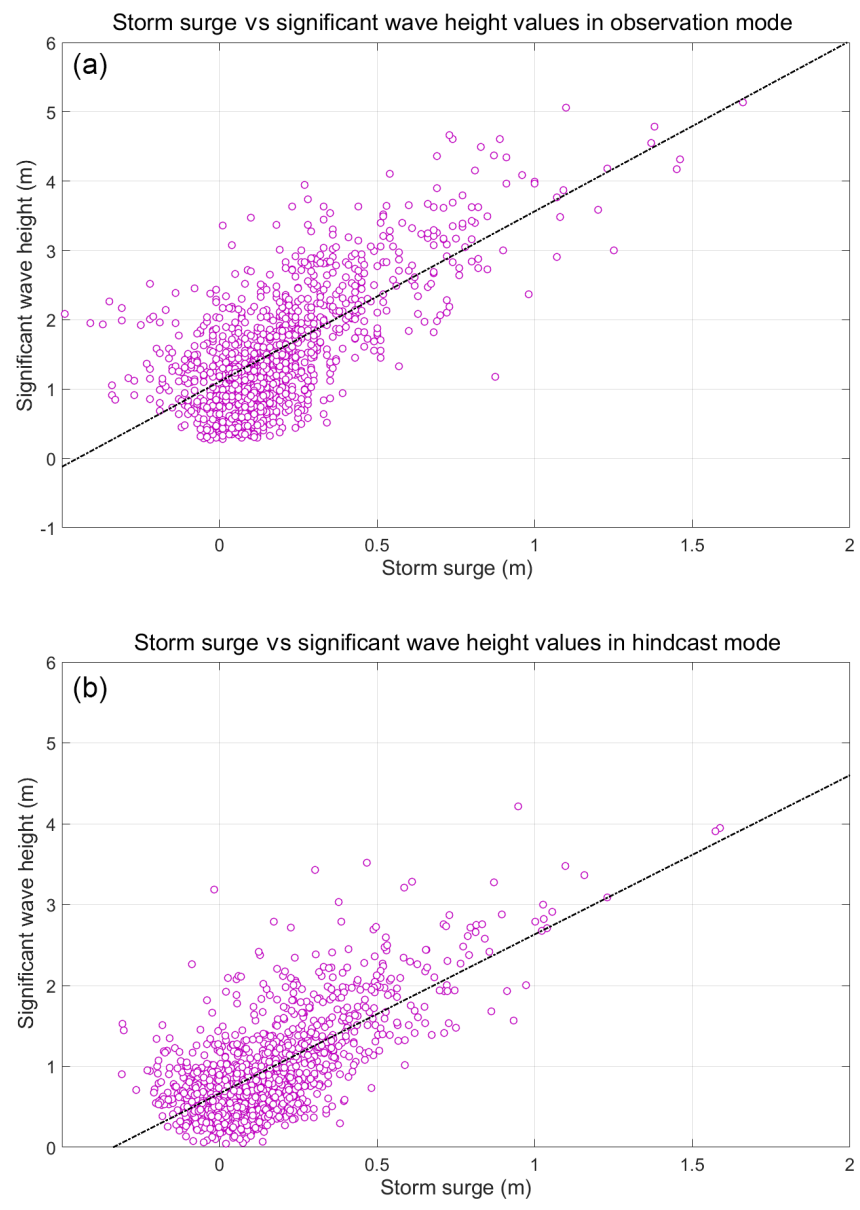

Figure 8. Scatter plots of storm surge against significant wave height in obs_com (a) and hind_com (b) for the common time interval of 1114 days.

\subsection{Validation of hindcasts in "compound" mode}

First, the (Pearson) correlation between the two source variables (surge and wave) in observation mode is estimated, while the same type of correlation is calculated in hindcast mode (see details in Table 1) for inter-comparison. Daily maximum (max24) values of storm surge observations collected at $\mathrm{HvH}$ station for the common time period (obs_com) are plotted against corresponding significant wave height observations recorded at the LiG buoy as shown in Fig. 8 (upper panel).

Observations of surge and wave seem to be well correlated, with a coefficient reaching a value of 0.70 . In hindcast mode (hind_com), the exact correlation value $(0.70)$ was found between surge and wave hindcasts during the selected common interval. Surge and wave values in hind_com are plotted in Fig. 8 (lower panel). In both obs_com and hind_com modes the maximum values of correlations were achieved in zero lag mode (i.e. during the same $24 \mathrm{~h}$ interval).

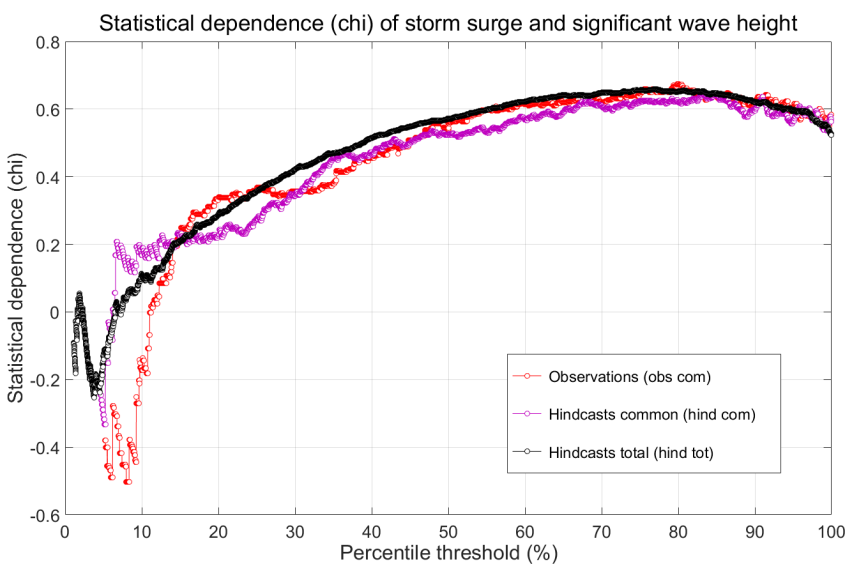

Figure 9. Statistical dependence $(\chi)$ of storm surge $(\mathrm{HvH})$ and significant wave height (LiG) max24 values in common obs_com and hind_com (1114 days) and in total hind_tot (12 753 days) mode.

Table 1. Details and abbreviations of data sets used in the study.

$\begin{array}{ll}\text { obs_com } & \text { Observations during the common period (1114 days) } \\ \text { hind_com } & \text { Hindcasts during the common period (1114 days) } \\ \text { hind_tot } & \text { Hindcasts during the total period (12 753 days) }\end{array}$

Similar results were found in the max 12 hind_com case, with a (slightly lower) correlation value reaching 0.69 in zero-lag mode. A slightly higher correlation value $(0.73)$ was found in zero-lag mode when the total 12753 daily max 24 data pairs of hindcasts (hind_tot) were used. This deviation should not be considered significant since a different number of data pairs was used. Similar (slightly lower) correlation values were found for the $\max 12$ hind_tot data pairs (0.71). Overall, it seems that hindcasts in this case were capable of resolving and estimating both the correct type and strength of correlation between source variables.

As in the case of correlations, the ability of hindcasts to correctly resolve the statistical dependence between surge and wave focusing on the upper (extreme) percentiles is investigated by inter-comparing dependencies estimated in obs_com and in hind_com (1114 days). Figure 9 shows the full range of $\chi$ values for all different types of data pairs considered in this study. The peak-over-threshold (POT) methodology (see details in the Statistical Supplement) was applied for a minimum 3-day separation of extremes, and an optimal selection of threshold was made, not allowing more than $\sim 2.3$ events per year to exceed it, resulting in quite stable $\chi$ graphs over a wide range of percentile values as shown in Fig. 9 (for obs_com, hind_com, and hind_tot), whereas due to the sparsity of data pairs, values of dependence in the area of lower and higher quantiles appear to be quite unstable (i.e. with abrupt fluctuations).

Similar (in harmony among them) strong values of $\chi$ between surge and wave were found for all three configurations (obs_com, hind_com, and hind_tot) in zero-lag mode as 
Table 2. Dependencies between surge and wave values for observations (obs_com) and hindcasts (hind_com) in common intervals and hindcasts over the total period (hind_tot). POT thresholds are shown in parentheses.

\begin{tabular}{rrr}
\hline obs_com & hind_com & hind_tot \\
\hline $0.5850(98.2 \%)$ & $0.5840(98.3 \%)$ & $0.5629(98.0 \%)$ \\
\hline
\end{tabular}

shown in Table 2. Similar results (for all three configurations) were also found when the same data pairs were considered for running the chiplot module of the statistical package $\mathrm{R}$ (as shown in Fig. S1 of the Statistical Supplement). Slightly lower (but still in harmony) values were found for max 12 case (in zero-lag mode).

The importance and implications of such high values of dependence can be demonstrated with an example such as the one presented in Sect. S7 of the Statistical Supplement by considering the total hindcast (hind_tot) series for surge $(\mathrm{HvH})$ and wave (LiG).

It should be pointed out that the real (correct) statistical dependence is estimated by utilizing the formula of Eq. (S4) in the Statistical Supplement over a long set of real data (observations) of storm surge coming from a tide gauge and real data of wave height coming from a close-by wave buoy. The tide gauge and wave buoy have to be relatively close for obvious reasons. Usually the tide gauge is in the vicinity of the port, while the wave buoy is suited some kilometres offshore in front of the port.

Besides observations (that are limited in time length), hindcasts can be used as in this case. It should be also evident by now that, even if hindcasts might be missing the exact magnitude of the extremes mainly due to the limited (model) resolution, the most important issue here is their ability to resolve and estimate the correct value of both correlation and dependence as it would have been estimated over real data (observations).

In the case of the RIEN of the Rhine River, the high level of agreement between the dependence estimated utilizing (surge and wave) observations and the one utilizing (surge and wave) hindcasts points to hindcasts being capable of resolving both the correct type and strength of dependence between the source variables.

Overall, considering the complexity of all physical drivers behind such dependencies that are focused intentionally on the upper percentiles where extremes reside, hindcasts of storm and wave seem to perform quite well in their ability to simulate observations and to correctly resolve the type and strength of both correlation and statistical dependence.

\subsection{Correlations and dependencies for southern coastal areas}

A necessary split of results had to be made for a better and easier visualization due to the relatively large amount of RIEN points to fit in one single table. This split also revealed the distinct differences between southern and northern coastal European areas. Details of both correlations and dependencies found over southern RIEN points are presented analytically in Tables S6 (based on Matlab routines) and S8 (based mainly on R routines) of the Technical Supplement. For the analysis of results, the ensemble mean value of $\chi$ (by averaging mat_chi, chiplot, and taildep values) is taken as a reference value. The different categories of correlation and dependence used later in the text refer to the categorization adapted by the Defra TR1 Report (2005), shown also (as an enclosed table) in Fig. 10.

In Table S6 (Technical Supplement), correlation (corr) and dependence (chi) values for both max 12 and max 24 intervals are presented together with critical threshold (thrs), significance (sig), and $95 \%$ confidence level (lower \& upper) $\max 24$ values. Regarding correlation values, a large amount of variability is evident in both $\max 12$ and max 24 modes. In max 12 mode, low $(0.05 \leq \chi<0.12)$ or even negative correlations were found over most coastal areas with the exception of Adriatic Sea RIENs and the RIEN of the Aven River (belonging to a higher category), whereas moderate $(0.12 \leq \chi<0.38)$ values of dependence $(\max 12)$ were estimated for most of those RIEN points. Such differences do not come as a surprise since dependence focuses selectively on the upper (extreme) percentiles and not on the full range of data pairs, meaning that surge and wave may have a considerable statistical dependence capable of modulating joint return period even if correlation in some cases is remarkably low (Drouet Mari and Kotz, 2004). Higher correlations were found in max 24 mode compared to max 12, although low (close to zero) and even negative values were estimated locally over the Balearic Sea, Alboran Sea, northen and western Iberian coasts, and Black Sea.

Referring to dependence, with the exception of the Foix RIEN point (belonging to the low category), the rest of the "comb" dependencies (last column of Table S8 of the Technical Supplement) fall into the moderate category $(0.12 \leq \chi<0.38)$. Besides dependence (chi), chibar values were estimated. Significance values and lower- and upperconfidence-interval values of $\chi$ were calculated as well. In Table S8 (Technical Supplement), a set of $\mathrm{R}$ values is shown based on chiplot (extRemes module) and taildep (evd module) routines. Relatively small differences were found in estimations of dependence based on Matlab and R routines. Such differences may be attributed to the methodology for selecting critical percentile thresholds and how to identify and confine POT extremes in every case, but, nevertheless, in almost all cases both Matlab and $\mathrm{R}$ routine estimations were found to belong in the same category. In addition, except for the Foix RIEN, both taildep and chiplot estimations of dependence fall well inside the confidence (95\%) intervals estimated by mat_chi routines.

Extensive lag tests were made for both correlation and dependence, revealing that the maximum strength of almost any 


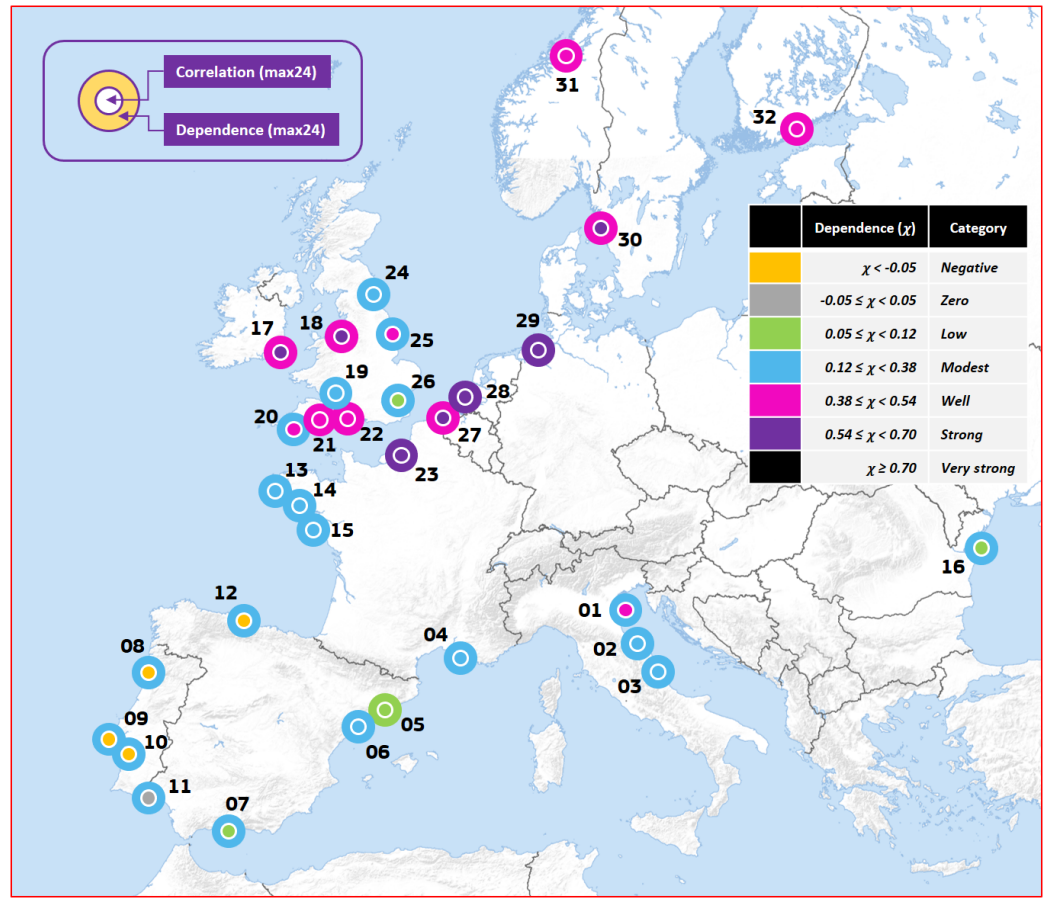

Figure 10. Correlation (corr) and dependence (chi) values valid for the max 24 interval.

compound surge-wave event tends to take place during the same max 24 or max 12 period (zero-lag mode). Exceptions were found for Rhône, Ebro, and Danube RIENs. In these cases surge values were (slightly) more highly correlated with wave values of the previous day. Further, the agreement of dependence values (among Matlab and $\mathrm{R}$ routines) became more pronounced as the signal (value of dependence) got stronger. The ensemble mean (comb) value of $\chi$ is used hereafter to define the category of dependence $(\max 24)$ in all relevant text and maps.

\subsection{Correlations and dependencies for northern coastal areas}

In Table S7 (Technical Supplement), correlation (corr) and dependence (chi) values for both $\max 12$ and max24 intervals are presented together with chibar, critical threshold (thrs), significance (sig), and values of $95 \%$ confidence levels (max24). Distinctly higher values were found than those over southern areas for both $\max 12$ and $\max 24$ cases. All values were achieved in zero lag mode (with the exception of Thames and Goeta RIENs reaching their highest values with a 1-day lag).

Apart from the Thames RIEN (having a negative correlation), all $\max 12$ correlations fall in the moderate category and above (corr $\geq 0.12$ ), with the top maximum value (0.59) of the Béthune RIEN belonging to the strong category $(0.54 \leq$ corr $<0.70)$. Even higher correlation values were found in max 24 mode with almost all values falling in the "well" category and above (corr $\geq 0.38$ ). Correlations be- longing to the "strong" category were estimated for a considerable number of RIENs over the Irish Sea, English Channel, North Sea, and Baltic Sea.

Contrary to findings over southern areas, smaller differences between correlation and dependence values were found over the northern areas for both $\max 12$ and $\max 24$ cases. Significantly high values of dependence belonging to the "well" category and above $(\chi \geq 0.38)$ between surge and wave were found over the Irish Sea, English Channel, North Sea, Norwegian Sea, and Baltic Sea in zero-lag mode (except for the Goeta RIEN with a 1-day lag time). Besides the Béthune RIEN in the English Channel, having a strong dependence $(0.65)$ in max 24 mode, strong dependencies were also found for Rhine (0.54) and Weser (0.55) RIENs. Such findings suggest that over the south coasts of the North Sea, when a surge extreme event is anticipated, probabilities are quite high for an extreme wave event to take place at the same time (as a compound event).

As in Table S8 (Technical Supplement), a set of dependence values for northern coastal areas based on $\mathrm{R}$ routines is shown in Table S9 (Technical Supplement). Once more, small differences were detected in estimations of statistical dependence between Matlab and $\mathrm{R}$ routines, but in almost all cases both Matlab and $\mathrm{R}$ routine estimations were found to fall in the same category. In addition, both taildep and chiplot estimations of dependence fall well inside the confidence $(95 \%)$ intervals estimated by mat_chi routines. As in Sect. 3.3, an ensemble mean value of chi contained in the last 
column of Table S9 (Technical Supplement) is considered as a reference value of dependence $(\max 24)$.

Results referring to the ensemble (comb) value of $\chi$ and correlation for max 24 cases over all RIEN points are shown in Fig. 10. The categorization applied in this study (shown graphically as an enclosed table in Fig. 10) is similar to the one introduced by the Defra TR1 Report (2005).

Lastly, a full set of lag tests was made for both correlation and dependence. It was found that the maximum strength of almost any compound (surge and wave) event tends to take place during the same $24 \mathrm{~h}(\max 24)$ time or during the same $12 \mathrm{~h}(\max 12)$ period corresponding to zero-lag mode. Exceptions were found for Thames (UK) and Goeta Aelv (SE) RIEN points with a 1-day lag ( 2 half-days in the case of $\max 12)$.

\subsection{Wind rose diagrams assessing the low-level flow characteristics during critical compound events}

The "prevailing wind" is the most common wind direction over an area, i.e. the direction of wind with the highest frequency (AMS, 2017), whereas the "dominant wind" is the direction of the strongest wind that might blow from a different direction than the prevailing wind, i.e. from a less common direction (Thomas, 2000). The periods most frequently used for the estimation of prevailing and dominant winds are the observational day, month, season, and year. Methods for determination vary from a simple count of periodic observations to the computation of a wind rose.

Extreme compound surge and wave events are unavoidably linked to severe weather conditions. These conditions include very strong winds and low atmospheric pressure that is caused mainly by intense storms. Focusing on the lowlevel circulation, a set of wind rose diagrams was compiled for all RIEN points utilizing ERAI reanalysis winds spanning over the total period of 12753 days.

ERAI winds refer to the four main synoptic hours (00:00, 06:00, 12:00, and 18:00 UTC) of reanalysis. From such fourterm (daily) sets the maximum speed was estimated and kept together with its corresponding direction to be used in the wind rose diagrams. A wind rose is an information-packed plot providing frequencies of wind direction and speed. A wind rose diagram can quickly indicate both the prevailing wind, referring to the principal or most common wind direction (having the highest percentage of occurrence), and the dominant wind, indicating the direction of the highest wind speed. Examples of wind roses are given in Fig. 11, referring to daily maximum winds for the Rhône River RIEN during 12753 days that may be taken as "clima" conditions (i.e. average (mean) conditions; upper panel) and during the top 80 ( $\sim 2.3$ yearly events over 35 years) compound events (lower panel) that may be considered as extreme compound mode conditions.

From Fig. 11 (upper panel) it is obvious that the clima prevailing (highest frequency) wind is north-northwest
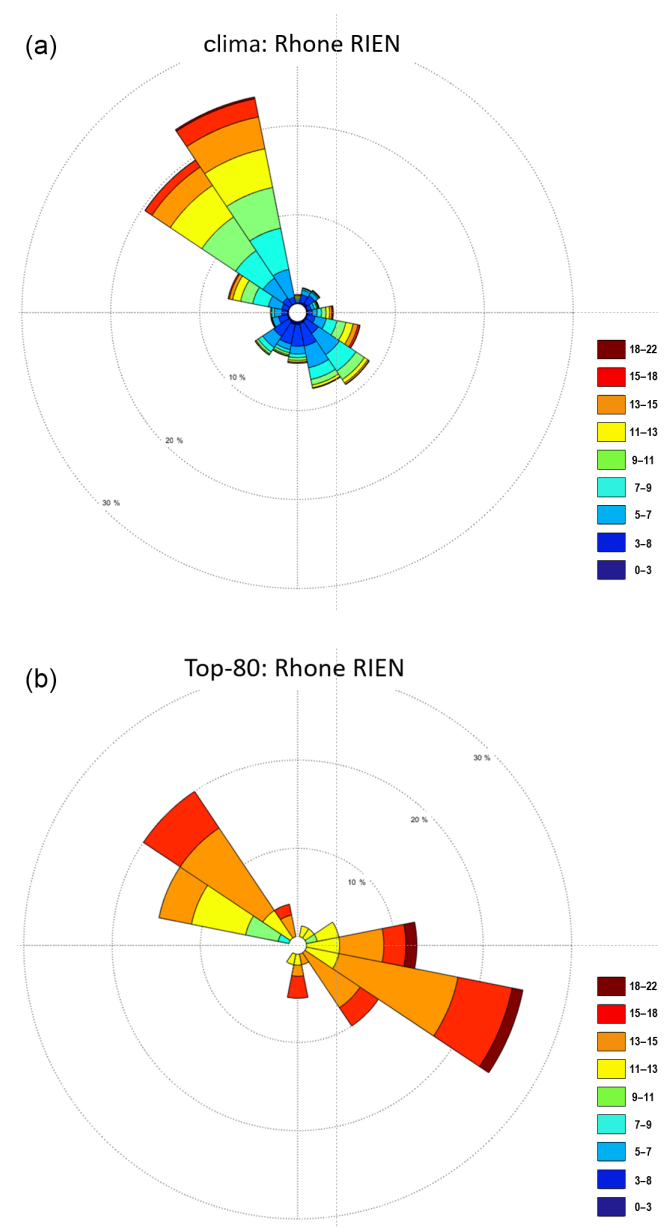

Figure 11. Statistical "clima" average (a) and top 80 extreme compound (b) daily maximum wind roses for the Rhône River RIEN.

(NNW), a local type of wind named "mistral" (www.cs. mcgill.ca/ rwest/wikispeedia/wpcd/wp/w/Wind.htm, last access: 12 May 2018). The dominant wind (highest intensity) also is of a similar type (mistral) blowing from a northwest (NW) direction. Mistral is a strong northerly wind blowing over the Gulf of Lion (GoL) and Rhône Valley. The air is usually dry, bringing bright and clear weather with freezing temperatures to the south of France. The mistral often reaches gale force especially in winter and is capable of raising heavy sea conditions in a short space of time.

The same type of diagram was produced for the top 80 compound events (lower panel of Fig. 11), revealing a quite different story. The prevailing wind does not belong to the mistral "family" since it clearly comprises southeast components of another local wind named "marin" (www.cs. mcgill.ca/ rwest/wikispeedia/wpcd/wp/w/Wind.htm, last access: 12 May 2018). Marin is a strong wind in the area of GoL blowing from southeasterly directions, and it is next in frequency and importance to the mistral wind. It is generally warm, moist and cloudy, with rain and heavy weather, and is 
Table 3. Prevailing and dominant winds in clima and top 80 extreme compound mode.

\begin{tabular}{ll|ll|ll|ll|ll|ll}
\hline & & \multicolumn{2}{c|}{ clima } & \multicolumn{2}{c|}{ Top 80 } & & \multicolumn{2}{c|}{ clima } & \multicolumn{2}{c}{ Top 80 } \\
\hline \multicolumn{1}{l|}{} & RIEN & Prev. & Domi. & Prev. & Domi. & & RIEN & Prev. & Domi. & Prev. & Domi. \\
\hline 1 & Po & NE & ENE & ESE & NE & 17 & Owena & SSW & WSW & SSW & WSW \\
2 & Metauro & NE & NE & NE & NE & 18 & Mersey & WSW & W & SW & NNW \\
3 & Vibrata & NNE & SSE & SSE & ENE & 19 & Severn & WSW & SW & SSW & SSE \\
4 & Rhône & NNW & NW & ESE & ESE & 20 & Tamar & WSW & WSW & SSW & WSW \\
5 & Foix & S & NNW & WNW & NE & 21 & Exe & SW & WSW & SSW & SW \\
6 & Ebro & NW & NW & SSW & NW & 22 & Avon & SW & SW & SSW & SW \\
7 & Velez & ESE & E & E & E & 23 & Béthune & WSW & SW & SW & SW \\
8 & Douro & NNW & NNW & SW & SW & 24 & Tyne & WSW & SSE & SW & WSW \\
9 & Tagus & NNW & NW & SW & NW & 25 & Humber & SW & W & NNW & W \\
10 & Sado & NNW & NW & SW & S & 26 & Thames & SW & W & N & SSW \\
11 & Guadiana & NNW & W & SSW & SW & 27 & Schelde & WSW & WSW & W & WSW \\
12 & Sella & NE & WSW & SW & WSW & 28 & Rhine & WSW & WSW & W & WSW \\
13 & Moros & SW & SSW & WSW & W & 29 & Weser & WSW & WSW & WSW & WSW \\
14 & Aven & SW & WSW & SSW & WSW & 30 & Goeta & WSW & W & SW & NNW \\
15 & Blavet & SW & WSW & SSW & WSW & 31 & Orkla & SSE & WSW & WSW & WSW \\
16 & Danube & NNW & NNE & ENE & NNE & 32 & Vantaa & SW & SSE & ENE & N \\
\hline
\end{tabular}

associated with depressions (storms) that enter the GoL area from the west or southwest after traversing southern France and northern Spain.

The implication of such findings is that, although the prevailing and dominant wind in clima mode is of the mistral type, most of the top 80 extremes take place under marin conditions in a relatively stronger wind environment (compared to mistral conditions). On the other hand, mistral conditions are also found to be responsible for a considerable percentage of top 80 events accompanied by winds of lesser intensity (compared to the marin ones). Similar detailed wind (clima and top 80) roses were produced for the rest of the RIEN points. Distinct differences between southern and northern coastal areas are once more pronounced, revealing relatively stronger intensity flow characteristics over the northern areas.

Details of clima and top 80 flow characteristics are contained in Table 3. A possible exploitation of such information referring to both prevailing and dominant low-level flow characteristics should be considered significant and kept in mind when such extreme events possibly driven by intense storm outbreaks are anticipated over the area of interest (in forecast mode).

Not all prevailing and dominant directions contained in Table 3 fall in the perpendicular onshore category. Especially for the RIEN points of the southern North Sea, wind directions appear to be more SWS instead of having more northerly directions, and this is because combined events had to be de-clustered. This means that a compound event lasting more than 1 day had to be counted as one event even if this event could have lasted for a few days. After this necessary de-clustering, all cases of compound events refer to the first day of the event (the first day that both storm surge and wave height found to be above a predefined critical threshold).

With such an approach, a compound event is considered only once, and no other (another) event is taken into account for the next 3 days (even if the same event continues to exist longer than a day). Both prevailing and dominant directions refer to the maximum daily intensity; if we consider the most common case of an approaching barometric low (storm), the wind in the beginning is more WSW, whereas with the passage of the storm it tends to veer to a more northwestern (northern) direction, becoming more perpendicular to the coast.

Besides wind roses, the critical time period of the top 80 events was investigated. For instance, in the case of the Rhône River, most marin (east-southeasterly flow) and mistral (northwesterly flow) top 80 extreme compound events took place during the cold period of the year. Such a critical period was confined to October-March, containing $91 \%$ of all top 80 compound events.

Similarly, the critical period of top 80 events was calculated for the rest of the RIEN points based on monthly frequencies of occurrence (Table 4). This critical interval comprised mostly cold months. There were even cases such as for the RIEN of the Rhine (NL) and Schelde (BE) where all $(100 \%)$ top 80 compound events took place during the cold period (September to April). During these critical intervals (Table 4) there appears to exist a clear tendency of the northern extreme compound events to take place mostly with southwestern components of stronger wind intensity (compared to southern events). This tendency of both prevailing and dominant winds to be clustered around the southwestern quadrant is more pronounced over the Irish Sea, English Channel, North Sea, and Norwegian Sea. 
The validity of such findings is briefly investigated. For the Irish Sea, extreme surge conditions especially on its eastern side are generated by southwesterly to westerly winds as documented by Brown et al. (2010). For the English Channel, this southwestern signature is compatible with the path of (extratropical) storms that tend to generate large surges (Henderson and Webber, 1977). For the North Sea such a southwestern preference seems to partly contradict the fact that the largest wave events occur in the central North Sea when a low-pressure system is situated over southern Scandinavia (such as the one shown in Fig. 6), giving rise to a long northerly fetch associated with strong northerly winds. An obvious explanation could be that southerly-wind events can also create large wave heights despite their limited fetch, since southerly-wind events are associated with the existence of zonal jets (embedded in extratropical cyclones) that intensify rapidly in the left exit region of the jet stream as indicated by Bell et al. (2017). Besides this, depths in the southern North Sea are only about $40 \mathrm{~m}$ on average, adding to the fact that wind stress is particularly effective in piling up water against the coast in the shallow water as the effect is inversely proportional to water depth (Wang et al., 2008).

It should be kept in mind that, besides the prevailing and dominant wind directions responsible for most compound extremes, there still exist additional critical directions linked to extremes. For instance in the area of the German Bight (southern North Sea), northwestern wind components (visible in the wind rose for the Weser RIEN) have been identified as having a significant link to both surge and wave extremes (Staneva et al., 2016).

Lastly, for the Norwegian Sea, observations seem to fully support these findings as documented in an earlier work of Gjevik and Røed (1976), showing that large storm surges are caused by strong southwesterly winds acting along a large section of the Norwegian coast.

Overall, the low-level flow characteristics (prevailing and dominant winds) appear to be first in harmony with the transient nature of (extratropical) storms and their footprints (storm tracks). This seems to be consistent with similar findings (even if they apply for different pair of variables) in the Defra TR1 and TR3 reports and in Svensson and Jones (2002, 2004a, b, 2005), documenting that (storm) surge and (river) flow dependence appears to be largely influenced by the storm track of the depressions, although it should be kept in mind that a thorough understanding of all factors leading to such compound events is beyond the scope of this study.

\section{Discussion}

The possibility of utilizing statistical dependence methods in coastal flood hazard calculations is investigated, since flood risk is rarely a function of just one source variable but usually two or more. Source variables in most cases are not indepen-
Table 4. Critical period and percentage of occurrence for top 80 compound events.

\begin{tabular}{ll|lr|ll|lr}
\hline & & \multicolumn{2}{|c|}{ Top 80 } & & & \multicolumn{2}{c}{ Top 80 } \\
\hline & RIEN & Period & $\%$ & & RIEN & Period & $\%$ \\
\hline 1 & Po & Oct-Mar & 91 & 17 & Owena & Oct-Mar & 93 \\
2 & Metauro & Oct-Mar & 88 & 18 & Mersey & Oct-Mar & 96 \\
3 & Vibrata & Oct-Mar & 91 & 19 & Severn & Sep-Apr & 91 \\
4 & Rhône & Oct-Mar & 91 & 20 & Tamar & Sep-Apr & 94 \\
5 & Foix & Sep-Apr & 94 & 21 & Exe & Sep-Mar & 91 \\
6 & Ebro & Oct-Apr & 88 & 22 & Avon & Oct-Mar & 93 \\
7 & Velez & Oct-May & 98 & 23 & Béthune & Oct-Mar & 93 \\
8 & Douro & Oct-Apr & 88 & 24 & Tyne & Oct-Mar & 96 \\
9 & Tagus & Oct-Apr & 94 & 25 & Humber & Oct-Apr & 98 \\
10 & Sado & Oct-Apr & 97 & 26 & Thames & Oct-Apr & 91 \\
11 & Guadiana & Oct-Apr & 93 & 27 & Schelde & Sep-Apr & 100 \\
12 & Sella & Sep-Apr & 93 & 28 & Rhine & Sep-Apr & 100 \\
13 & Moros & Sep-Apr & 94 & 29 & Weser & Oct-Apr & 97 \\
14 & Aven & Sep-Apr & 91 & 30 & Goeta & Sep-Mar & 98 \\
15 & Blavet & Sep-Apr & 93 & 31 & Orkla & Sep-Mar & 95 \\
16 & Danube & Nov-Apr & 91 & 32 & Vantaa & Sep-Jun & 98 \\
\hline
\end{tabular}

dent as they may be driven by the same weather event, so their dependence $(\chi)$, which is capable of modulating their joint return period, has to be estimated before the calculation of their joint probability. The source variable pairs presented here are storm surge and wave height, and their correlation and dependence were assessed over 32 RIEN points along European coasts. It should be noted that correlation and dependence may differ substantially from one another. This is because correlation is estimated over the full range of percentiles, whereas dependence is focused on the upper (extreme) percentiles.

In the absence of widespread coincident long-term measurements of surge and wave, a set of $\sim 35$-year (12753 days) hindcasts was compiled. Storm surge hindcasts were performed by utilizing the hydrodynamic model Delft3D-FLOW, while wave hindcasts were generated with the ECWAM wave (stand-alone) model. Although in some cases extreme surge and wave hindcast levels were underestimated, the overall performance of both surge and wave hindcasts is considered satisfactory. Further, a joint validation in compound mode was made over the area of Hook van Holland $(\mathrm{HvH})$ taking into account real measurements of both tides and waves. Overall, hindcasts for the common period of observations (1114 days) were found capable of resolving and estimating both the correct type and strength of correlation and dependence between source variables.

Since such compound validation is impossible to repeat for all RIEN points, caution with the exact levels of correlation and dependence should be borne in mind for the rest of the RIEN points.

Results are presented by means of analytical tables and maps for each RIEN point and can be used to calculate the joint return period by inserting the value of dependence $(\chi)$ in a simple formula (Eq. S12 of the Statistical Sup- 
plement) containing the individual return periods of source variables as documented in Hawkes (2004), Meadowcroft et al. (2004), White (2007), the Australian Rainfall \& Runoff Project 18 (2009), and Petroliagkis et al. (2016). Some limitations of Eq. (S12) (Statistical Supplement) can be overcome if a more complete formula is used, such as Eq. (2.15) from White's (2007) thesis, but this is beyond the scope of the current study.

Further, a necessary split of results revealed distinct differences between southern and northern coastal European areas since significantly higher values of correlation and dependence were found over northern sea areas. Overall, significant correlations and dependencies between surge and wave in the categories "well" and above $(\geq 0.38)$ were found over the Irish Sea; English Channel; and the south coasts of the North Sea, Norwegian Sea, and Baltic Sea in a zero-lag mode. Over these areas, dependencies reaching locally up to 0.65 (Béthune RIEN) stress the fact that, when the first variable (surge) has an extreme value, there exists a high probability that the other one (wave) will also produce an extreme level. For the rest of the RIEN points mostly positive moderate $(0.12 \leq \chi<0.38)$ dependence values were estimated, although a considerable number of them had correlations that were almost zero or even negative. This does not come as a surprise since even in cases of very low correlation there may exist a considerable amount of tail dependence.

Based on these results, it seems that compound events over northern sea areas are mostly driven (forced) by a common extreme wind event resulting in a high value of dependence between surge and wave, whereas a large contribution of atmospheric pressure affecting only storm surge might be one among other reasons for low dependence values over southern sea areas.

An effort to inter-compare these results with previous studies was made, although there were very few relevant journal papers focusing on correlations and dependencies over such a wide range of coastal areas. A relevant study (thesis) by Kergadallan (2015) for the coasts of France has documented that the surge wave dependence is medium along the Mediterranean coast, whereas dependence values were found to be more pronounced in the English Channel and along the Atlantic coast, which seems consistent with the findings of this study.

Other relevant references pointed to a series of UK Defra/Environmental Agency reports (2003 - Defra TR0; 2005 - Defra TR1, Defra TR2, and Defra TR3), hereafter referenced as TRx reports. This set of reports (TRx), however, refers to a different measure of dependence constituting a "special" correlation coefficient, $\rho$, above a chosen threshold (90\%). Over UK coasts, such values of $\rho$ were found to be positive like the set of $\chi$ values of this study but considerable higher. Such differences could be attributed partly to the fact that $\chi$ values were estimated by considering a quite different (POT) threshold from the one (90\%) used in $\rho$ estimations. It could also be attributed to the different nature (methodology of estimation) between $\chi$ and $\rho$, since it is clearly mentioned in the TR1 Report that different statistical models underlie $\chi$ and $\rho$ values that could cause considerable distortion when converting from one parameter to the other.

Above all, it appears that such values of $\rho$ (coming from TRx reports) should not be considered as reliable statistical dependence $(\chi)$ values as they point to overestimated levels. In support of this, I refer to the methodology of estimating statistical dependence $\chi(u)$ by Coles (2001) utilizing a set of reference data for surge and wave over the Port of Newlyn (Cornwall, UK). Results taken from Fig. 8.11 (Coles, 2001) suggest a dependence value $\sim 0.35$ as $\chi(u)$ clearly tends to this value for the upper percentiles. This is very close to the estimation of this study for the RIEN of the Tamar River $(0.34)$ and significantly different from the value found in Table 4.4 of the TR1 Report, suggesting a value of $\rho$ higher than 0.60 .

A further investigation into the low-level flow characteristics of extreme compound events was conducted for a possible collection of forecasting "rule-of-thumb" guidelines. First, a set of $10 \mathrm{~m}$ wind roses was compiled utilizing ERAI wind terms over the total period of 12753 days. These winds refer to the four main synoptic hours $(00: 00,06: 00,12: 00$, and 18:00 UTC) based on which the daily maximum speed and its corresponding direction were defined and used for producing a set of clima wind roses for all RIENs. Based on such clima wind roses, the estimation of the prevailing (highest frequency) and dominant (highest intensity) winds was possible. In addition, the 80 most extreme (top 80) compound events were defined by applying POT methodology and allowing a maximum number $(\sim 2.3)$ of compound events on an annual basis. A set of wind roses in such extreme mode was assembled, revealing distinct differences between clima and top 80 events in many cases (Table 3). For instance, in the case of the Rhône River RIEN, the clima prevailing average conditions were of mistral (northwestern) type conditions, whereas the top extremes (top 80 ) were mostly of marin (southeastern) type conditions.

Detailed wind roses (top 80 mode) were produced for the rest of the RIEN points using a common wind speed scale. It seems that there is a clear tendency of the northern extreme compound events to take place mostly with southwestern components of stronger wind intensity (compared to the southern ones), especially during the cold months. This appears to be in harmony with the transient nature of winter storms and their storm tracks, as already indicated in Svensson and Jones (2004a, b) in a similar analysis for surge and discharge compound events around Britain.

It should be noted that not all prevailing and dominant directions contained in Table 3 fall in the perpendicular onshore category. Especially for the RIEN points of the southern North Sea, wind directions appear to be more SWS instead of having more northerly directions, and this is because combined events had to be de-clustered. This means that a compound event lasting more than 1 day had to be counted 
as one event even if this event could have lasted for a few days. After this necessary de-clustering, all cases of compound events refer to the first day of the event. With such an approach, a compound event is considered only once, and no other event is taken into account for the next 3 days. Both prevailing and dominant directions refer to the maximum daily intensity; if we consider the most common case of an approaching barometric low (storm), the wind in the beginning is more WSW, whereas with the passage of the storm it tends to veer to a more northwestern (northern) direction, becoming more perpendicular to the coast.

Besides the relevant link between transient storm systems and compound events, the morphological and topographical characteristics of RIEN areas appear to play a significant role in the genesis and evolution of such extremes. For instance, in addition to the local circulation systems such as the mistral and marin winds in the case of the Rhône River RIEN, a similar pattern was seen with the bora (northeastern) and sirocco (southeastern) winds providing the main dominant and prevailing (respectively) flows during the top $80 \mathrm{com}$ pound events over the Po RIEN (northern Adriatic Sea).

The critical time period of top 80 events was also estimated based on monthly frequency values of occurrence. This critical interval comprised mostly cold months (Table 4). There were even cases such as for the Rhine RIEN (NL) and Schelde RIEN (BE) where all (100\%) top 80 compound events took place during the cold period (September to April).

\section{Conclusions}

In the absence of widespread coincident long-term measurements of surge and wave, a set of $\sim 35$-year hindcasts was compiled to assess the correlation and statistical dependence over 32 river ending (RIEN) points along European coasts. A joint validation in compound mode was made over the area of Hook van Holland, taking into account real measurements of both tides and waves. Hindcasts were found capable of resolving and estimating both the correct type and strength of correlation and dependence between source variables.

Since such compound validation is impossible to repeat for all RIEN points, caution with the exact levels of correlation and dependence should be borne in mind for the rest of the RIEN points.

Results are presented by means of analytical tables and maps for each RIEN point and can be used to calculate the joint return period by inserting the value of dependence $(\chi)$ in a simple formula containing the individual return periods of source variables.

A necessary split of results revealed distinct differences between southern and northern coastal European areas since significantly higher values of correlation and dependence were found over northern sea areas with compound events taking place in the same max 12 (during half a day) or max 24 (daily) interval in a zero-lag mode. More specifically, strong values of positive correlations and dependencies were found over the Irish Sea; English Channel; and south coasts of the North Sea, Norwegian Sea, and Baltic Sea, with compound events taking place in a zero-lag mode. For the rest of the RIEN points, mostly positive moderate dependence values were estimated even if a considerable number of them had correlations of almost zero or even a negative value. These results seem to be in agreement with results from relevant studies over the coasts of France documenting that the surge wave dependence is medium (moderate) along the Mediterranean coast, whereas dependence values are more pronounced in the English Channel and along the Atlantic coast. Another similar study over the Tamar River (UK) has also suggested values close to these estimations of moderate dependence.

Based on these results, it seems that compound events over northern sea areas are mostly driven (forced) by a common extreme wind event resulting in a high value of dependence between surge and wave, whereas a large contribution of atmospheric pressure affecting only storm surge might be one among other reasons for low dependence values over southern sea areas.

A further investigation into the low-level flow characteristics of extreme compound events was conducted for a possible collection of forecasting rule-of-thumb guidelines. Detailed wind roses (in extreme mode) were produced for all RIEN points, using a common wind speed scale. It seems that there is a clear tendency of the northern extreme compound events to take place mostly with southwestern components of stronger wind intensity (compared to the southern ones), especially during the cold months. This appears to be in harmony with the transient nature of winter storms and their storm tracks as already indicated in similar analyses for surge and discharge compound events around Britain.

Besides the relevant link between transient storm systems and compound events, the morphological and topographical characteristics of RIEN areas appears to play a significant role in the genesis and evolution of such extremes.

The critical period of extreme-mode events was also estimated based on monthly frequency values of occurrence. This critical interval found to comprise mostly cold months, while there were even cases such as for the Rhine RIEN (NL) and Schelde RIEN (BE) where all (100\%) top 80 compound events took place during the cold period (September to April).

This work has been the first step of studying and investigating joint probabilities and return periods of compound events in a relatively low-resolution environment. Having this in mind, results referring to dependence estimations should be considered valid for coastal areas up to a certain distance (a few kilometres) away from the shoreline. Nevertheless, maps and tables can be used to get a valuable indication of the possibility for a combined (compound) hazard based on how the source variables are related (though statistical dependence) over various coastal areas of Europe. 
A thorough estimation of the design conditions in the coastal zone would require the inclusion of more primary and proxy variables in a higher-resolution environment. For instance, in addition to the significant wave height, the maximum wave height or/and the period or/and the direction of waves should be also considered. Another important point here is the effect of seasonal circulation and water-mass distribution (currents and tides) besides the prevailing weather system and atmospheric circulation contained in relevant weather maps.

Data availability. Climatic data used in the study are publicly available at http://data.jrc.ec.europa.eu/dataset/jrc-liscoast-10013 (Petroliagkis, 2018).

\section{The Supplement related to this article is available online at https://doi.org/10.5194/nhess-18-1937-2018- supplement.}

Competing interests. The author declares that he has no conflict of interest.

Acknowledgements. Jean-Raymond Bidlot (ECMWF) is to be gratefully thanked for providing the set of wave hindcasts and in situ wave observation data besides valuable guidance and suggestions. Evangelos Voukouvalas (Joint Research Center, JRC) is to be thanked for providing the set of storm surge hindcasts. A long list of JRC colleagues should be also thanked for their invaluable help and support during the Exploratory Research Project Coastal-AlertRisk (CoastAlRisk) of JRC. The CoastAlRisk project (2015-2016) was an initial effort of developing the first global integrated coastal flood risk management system with emphasis on such compound events, by linking satellite monitoring; coupled wave, tide, and surge forecasting; inundation modelling; and impact analysis.

Edited by: Uwe Ulbrich

Reviewed by: three anonymous referees

\section{References}

AMS (American Meteorological Society) Glossary: Prevailing Wind. Glossary of Meteorology, available at: http:// glossary.ametsoc.org/wiki/Prevailing_wind_direction (last access: 12 May 2018), 2017.

Australian Rainfall \& Runoff Project 18: Coastal Processes and Severe Weather Events: Discussion Paper, Water Technology report to Australia Rainfall \& Runoff (2009) referring to the report of Department of Science, IT, Innovation and the Arts - Science Delivery (October 2012) "Coincident Flooding in Queensland: Joint probability and dependence methodologies", available at: https://trove.nla.gov.au/work/180724742?q\&versionId= 196781622 (last access: 12 May 2018), 2009.
Beersma, J. J. and Buishand, T. A.: Joint probability of precipitation and discharge deficits in the Netherlands, Water Resour. Res., 40, W12508, https://doi.org/10.1029/2004WR003265, 2004.

Bell, R. J., Gray, S. L., and Jones, O. P.: North Atlantic storm driving of extreme wave heights in the North Sea, J. Geophys. Res.-Oceans, 122, 3253-3268, https://doi.org/10.1002/2016JC012501, 2017.

Bevacqua, E., Maraun, D., Hobæk Haff, I., Widmann, M., and Vrac, M.: Multivariate statistical modelling of compound events via pair-copula constructions: analysis of floods in Ravenna (Italy), Hydrol. Earth Syst. Sci., 21, 2701-2723, https://doi.org/10.5194/hess-21-2701-2017, 2017.

Bidlot, J.-R.: Present status of wave forecasting at ECMWF, Proceeding from the ECMWF Workshop on Ocean Waves, 25-27 June 2012, ECMWF, Shinfield Park, Reading, UK, 2012.

Bidlot, J.-R., Janssen, P., and Abdalla, S.: Impact of the revised formulation for ocean wave dissipation on ecmwf operational wave model, ECMWF Techn. Memo. No. 509, ECMWF, Reading, UK, 27 pp., 2006.

Blank, L.: Statistical Procedures for Engineering, Management, and Science, McGraw-Hill, Inc. New York, NY, USA, 1982.

Brown, J. M., Souza, A. J., and Wolf, J.: An investigation of recent decadal-scale storm events in the eastern Irish Sea, J. Geophys. Res., 115, C05018, https://doi.org/10.1029/2009JC005662, 2010.

Buishand, T. A.: Bivariate extreme-value data and the station-year method, J. Hydrol., 69, 77-95, 1984.

Coles, S. G.: An Introduction to Statistical Modelling of Extreme Values. Springer Series in Statistics, Springer Verlag London, 208 pp., 2001.

Coles, S. G., Heffernan, J., and Tawn, J. A.: Dependence measures for extreme value analyses, Extremes, 2, 339-365, 2000.

Currie, J. E.: Directory of coefficients of tail dependence, Department of Mathematics and Statistics Technical Report, ST-99-06, Lancaster University, 1999.

Dee, D. P., Uppala, S. M., Simmons, A. J., Berrisford, P., Poli, P., Kobayashi, S., Andrae, U., Balmaseda, M. A., Balsamo, G., Bauer, P., Bechtold, P., Beljaars, A., van de Berg, L., Bidlot, J., Bormann, N., Delsol, C., Dragani, R., Fuentes, M., Geer, A. J., Haimberger, L., Healy, S. B., Hersbach, H., Hólm, E.V., Isaksen, L., Kallberg, P., Köhler, M., Matricardi, M., McNally, A. P., Monge-Sanz, B. M., Morcrette, J.-J., Park, B. K., Peubey, C., de Rosnay, P., Tavolato, C., Thépaut, J.-N., and Vitart F.: The ERA-Interim reanalysis: configuration and performance of the data assimilation system, Q. J. Roy. Meteor. Soc., 137, 553-597, https://doi.org/10.1002/qj.828, 2011.

Defra TR0 Report (by P. J. Hawkes): Extreme water levels in estuaries and rivers: the combined influence of tides, river flows and waves, R \& D Technical Report FD0206/TR1 to Defra, HR Wallingford, UK, available at: http://randd.defra.gov. uk/Document.aspx? Document=FD0206_5270_TRP.pdf (last access: 12 May 2018), 2003.

Defra TR1 Report (by P. J. Hawkes and C. Svensson): Joint probability: dependence mapping \& best practice, R \& D Final Technical Report FD2308/TR1 to Defra, HR Wallingford and CEH Wallingford, UK, available at: http://evidence.environment-agency.gov.uk/FCERM/Libraries/ FCERM_Project_Documents/FD2308_3428_TRP_pdf.sflb.ashx (last access: 12 May 2018), 2005. 
Defra TR2 Report (by P. J. Hawkes): Use of joint probability methods in flood management: a guide to best practice, R \& D Technical Report FD2308/TR2 to Defra, HR Wallingford, UK, available at: http://www.estuary-guide.net/pdfs/FD2308_3429_TRP. pdf (last access: 12 May 2018), 2005.

Defra TR3 Report (by C. Svensson and D. A. Jones): Joint Probability: Dependence between extreme sea surge, river flow and precipitation: a study in south and west Britain, Defra/Environment Agency R \& D Technical Report FD2308/TR3, 62 pp. + appendices, available at: http://evidence.environment-agency.gov.uk/FCERM/Libraries/ FCERM_Project_Documents/FD2308_3430_TRP_pdf.sflb.ashx (last access: 12 May 2018), 2005.

Deltares Delft3D-FLOW: Simulation of multi-dimensional hydrodynamic flows and transport phenomena, including sediments, User Manual, Deltares, Delft, the Netherlands, 2014.

Drouet Mari, D. and Kotz, S.: Correlation and Dependence, Imperial College Press, London, 2004.

ECMWF: IFS DOCUMENTATION - Cy41R1, Operational implementation 12 May 2015, PART VII: Wave Model, ECMWF IFS documentation, ECMWF, Shinfield Park, Reading, UK, 2015.

Gjevik, B. and Røed, L. P.: Storm surges along the western coast of Norway, Tellus, 28, 166-182, 1976.

Hawkes, P. J.: Use of joint probability methods for flood \& coastal defence: a guide to best practice, R\&D Interim Technical Report FD2308/TR2 to Defra, HR Wallingford, UK, available at: http://www.estuary-guide.net/pdfs/FD2308_3429_TRP.pdf (last access: 12 May 2018), 2004.

Hawkes, P. J. and Tawn, J. A.: Joint probability of waves and water levels: JOIN-SEA: A rigorous but practical new approach, Internal Document No. SR 537, HR Wallingford with Lancaster University, UK (originally dated Nov. 1998, re-issued with minor adjustments in final form May 2000), available at: http://eprints.hrwallingford.co.uk/701/1/ SR537-JOINSEA-Probablility-waves-water-HRWallingford. pdf (last access: 12 May 2018), 2000.

Hawkes, P. J., Svensson, C., and Surendran S.: The joint probability of pairs of variables relevant to flood risk: Dependence mapping and best practice, Defra Flood and Coastal Management Conference, University of York, available at: http://eprints.hrwallingford.co.uk/188/1/HRPP345_The_joint_ probability_of_pairs_of_variables_relevant_to_flood_risk_ dependence_mapping_and_best_practice.pdf (last access: 12 May 2018), 2005.

Henderson, G. and Webber, N. B.: Storm surges in the UK south coast, Dock Harbour Auth., 57, 21-22, 1977.

Horsburgh, K. J. and Wilson, C.: Tide-surge interaction and its role in the distribution of surge residuals in the North Sea, J. Geophys. Res., 112, C08003, https://doi.org/10.1029/2006JC004033, 2007.

IPCC: Managing the Risks of Extreme Events and Disasters to Advance Climate Change Adaptation. A Special Report of Working Groups I and II of the Intergovernmental Panel on Climate Change, edited by: Field, C. B., Barros, V., Stocker, T. F., Qin, D., Dokken, D. J., Ebi, K. L., Mastrandrea, M. D., Mach, K. J., Plattner, G.-K., Allen, S. K., Tignor, M., and Midgley, P. M., Cambridge University Press, Cambridge, UK, and New York, NY, USA, 582 pp., available at: https://www.ipcc.ch/
pdf/special-reports/srex/SREX_Full_Report.pdf (last access: 12 May 2018), 2012.

Joe, H.: Multivariate Models and Dependence Concepts, Chapman \& Hall, London, 1997.

Kergadallan, X.: Estimation of extreme marine sea levels with and without wave component along the French coasts, Mécanique des fluides [physics.class-ph], Université Paris-Est, France, 2015.

Klerk, W. J., Winsemius, H. C., Verseveld, W. J., van Bakker, A. M. R., and Diermanse, F. L. M.: The co-incidence of storm surges and extreme discharges within the Rhine-Meuse Delta, Environ. Res. Lett., 10, 035005, https://doi.org/10.1088/17489326/10/3/035005, 2015.

Meadowcroft, I., Hawkes, P. J., and Surendran, S.: Joint probability best practice guide: practical approaches for assessing combined sources of risk for flood and coastal risk managers, in: Proceedings from the Defra 39th Flood \& Coastal Management Conference, York, UK, July 2004, 6A.2.1-6A.2.12, 2004.

Merz, B., Elmer, F., and Thieken, A. H.: Significance of "high probability/low damage" versus "low probability/high damage" flood events, Nat. Hazards Earth Syst. Sci., 9, 1033-1046, https://doi.org/10.5194/nhess-9-1033-2009, 2009.

Nelsen, R. B.: An Introduction to Copulas, Springer-Verlag, New York, 1998.

Petroliagkis, T. I.: Hindcasts of storm surge and wave height over 32 river ending points, European Commission, Joint Research Centre (JRC) [Dataset] PID, available at: http://data.jrc.ec.europa.eu/ dataset/jrc-liscoast-10013 (last access: 4 July 2018), 2018.

Petroliagkis, T. I., Voukouvalas, E., Disperati, J., and Bidlot, J.: Joint Probabilities of Storm Surge, Significant Wave Height and River Discharge Components of Coastal Flooding Events, JRC Technical Report EUR 27824 EN, https://doi.org/10.2788/677778, 2016.

Phillips, B. T., Brown, J. M., Bidlot, J.-R., and Plater, A. J.: Role of Beach Morphology in Wave Overtopping Hazard Assessment, J. Mar. Sci. Eng., 5, 1, https://doi.org/10.3390/jmse5010001, 2017.

Reed, D. W.: Flood Estimation Handbook, Vol. 1: Overview, Institute of Hydrology, Wallingford, UK, 1999.

Sembiring, L., van Ormondt, M., van Dongeren, A., and Roelvink, D.: A validation of an operational wave and surge prediction system for the Dutch coast, Nat. Hazards Earth Syst. Sci., 15, 12311242, https://doi.org/10.5194/nhess-15-1231-2015, 2015.

Staneva, J., Wahle, K., Koch, W., Behrens, A., Fenoglio-Marc, L., and Stanev, E. V.: Coastal flooding: impact of waves on storm surge during extremes - a case study for the German Bight, Nat. Hazards Earth Syst. Sci., 16, 2373-2389, https://doi.org/10.5194/nhess-16-2373-2016, 2016.

Svensson, C. and Jones, D. A.: Dependence between extreme sea surge, river flow and precipitation in eastern Britain, Int. J. Climatol., 22, 1149-1168, 2002.

Svensson, C. and Jones, D. A.: Dependence between extreme sea surge, river flow \& precipitation: a study in south \& west Britain, R\&D Interim Technical Report FD2308/TR3 to Defra, CEH Wallingford, UK, available at: http://evidence.environment-agency.gov.uk/FCERM/Libraries/ FCERM_Project_Documents/FD2308_1135_INT_pdf.sflb.ashx (last access: 12 May 2018), 2003.

Svensson, C. and Jones, D. A.: Dependence between sea surge, river flow and precipitation in south and west Britain, Hydrol. Earth 
Syst. Sci., 8, 973-992, https://doi.org/10.5194/hess-8-973-2004, 2004a.

Svensson, C. and Jones, D. A.: Sensitivity to storm track of the dependence between extreme sea surges and river flows around Britain, in: Hydrology: Science and Practice for the 21st Century, Vol. 1, Proc. from the British Hydrological Society's international conference, London, UK, July 2004, 239a-245a (addendum), 2004b.

Svensson, C. and Jones, D. A.: Climate change impacts on the dependence between sea surge, precipitation and river flow around Britain, in: Proceedings from the Defra 40th Flood \& Coastal Management Conference, York, UK, July 2005, 6A.3.1-6A.3.9, 2005.

Sverdrup, H. U. and Munk, W. H.: Empirical and theoretical relations between wind, sea, and swell, T. Am. Geophys. Un., 27, 823-827, 1946.

Thomas, D. G.: Dictionary of physical geography, Blackwell, Ltd. Hoboken, New Jersey, USA, 2000.

Vousdoukas, M. I., Voukouvalas, E., Annunziato, A., Giardino, A., and Feyen, L.: Projections of extreme storm surge levels along Europe, Clim. Dynam., 47, 3171-3190, https://doi.org/10.1007/s00382-016-3019-5, 2016.
Wahl, T., Jain, S., Bender, J., Meyers, S. D., and Luther, M. E.: Increasing risk of compound flooding from storm surge and rainfall for major US cities, Nature Climate Change, 5, 1093-1097, 2015.

Wang, S., McGrath, R., Hanafin, J., Lynch, P., Semmler, T., and Nolan, P.: The impact of climate change on storm surges over Irish waters, Ocean Model., 25, 83-94, 2008.

White, C. J.: The use of joint probability analysis to predict flood frequency in estuaries and tidal rivers, PhD Thesis, p. 343, School of Civil Engineering and the Environment, University of Southampton, Southampton, UK, 2007.

Zheng, F., Westra, S., and Sisson, S. A.: Quantifying the dependence between extreme rainfall and storm surge in the coastal zone, J. Hydrol., 505, 172-187, 2013.

Zheng, F., Westra, S., Leonard, M., and Sisson, S. A.: Modelling dependence between extreme rainfall and storm surge to estimate coastal flooding risk, Water Resour. Res., 50, 2050-2071, 2014. 